

\title{
CARACTERIZAÇÃO DE FEIÇÕES MORFOLÓGICAS NO CANAL DO RIO JAGUARIBE: TRECHO LIMOEIRO DO NORTE-QUIXERÉ
}

\section{CHARACTERIZATION OF MORPHOLOGICAL FEATURES IN THE JAGUARIBE RIVER CANAL: LIMOEIRO DO NORTE-QUIXERÉ}

\author{
Gerliane Kelly de Sousa Coelho \\ Departamento de Geografia, Universidade Federal do Ceará \\ Rua Tenente Sebastião, 594, Limoeiro do Norte, Ceará, CEP: 62.930-000, Brasil \\ ORCID: 0000-0002-2570-6814 \\ E-mail: gerlianecoelho.geo@gmail.com
}

José Hamilton Ribeiro Andrade

Departamento de Ambiente, Tecnologia e Sociedade, Universidade Federal Rural do Semiárido Rua Coronel José de Brito, 420, Quixeré, Ceará, CEP: 62.920-000, Brasil

ORCID: 0000-0003-4576-0655

E-mail: hamilton.andrade@uece.br

\begin{tabular}{l} 
Informações sobre o Artigo \\
\hline Recebido (Received): \\
04/01/2019 \\
Aceito (Accepted): \\
26/05/2019
\end{tabular}

Palavras-chave:

Dinâmica fluvial. Barras e ilhas. Rios Jaguaribe.

\section{Keywords:}

River Dynamics. Bars and islands. Rivers Jaguaribe.

\section{Resumo:}

Os sucessivos eventos de erosão, transporte e deposição de sedimentos que ocorrem nos rios proporcionam a formação e evolução de feições morfológicas no canal e na planície de inundação, com características morfológicas recorrentes a região onde está inserida. Ainda que haja estudos de rios localizados no clima semiárido, com padrão entrelaçado e anabranching, principalmente na Austrália, existe uma carência metodológica para rios semiáridos brasileiro. A produção acadêmica sobre barras e ilhas está concentrada nos ambientes fluviais localizados em clima tropical, subtropical e temperado, baseado nesse contexto, o trabalho tem como objetivo analisar as características morfológicas de barras e ilhas no rio Jaguaribe-CE, trecho que vai da passagem molhada da barragem das pedrinhas no Município de Limoeiro do Norte até a passagem molhada de Sucurujuba em Quixeré, com recorte temporal 2001 a 2016 (16 anos). Para isso, o trabalho foi estruturado a partir de uma lógica sistêmica, com etapas de caracterização da área de estudo; trabalho de campo para levantamento fotográfico e coleta de sedimentos; fase de laboratório para análise granulométrica através dos processos de peneiramento mecânico e pipetagem; e etapa de gabinete destinada à coleta de dados de chuva e vazão e ao sensoriamento remoto e geoprocessamento. Os resultados obtidos através da análise das imagens orbitais mostraram que as principais mudanças evolutivas referentes ao crescimento da área observada aconteceram entre 2014 e 2016, período correspondente à seca prologada no Ceará, que teve início em 2012. Verificou-se que as ilhas mais largas possuem tendência de sedimentação lateral superior, devido ao barramento de fluxo que o próprio depósito faz. No que refere as barras laterais, foi observado que sua gênese é resultado de processos distintos, registrados em períodos chuvosos como 
2009, provocando a redistribuição sedimentar de partículas por todo o leito, e em anos secos como 2016, pela exposição de bancos arenosos antes submersos que faziam parte do leito molhado. As barras de planície, em sua totalidade, apresentaram crescimento areal em $100 \%$ dos depósitos, devido sua resistência frente a processos erosivos. Ademais, considerou-se necessária a adoção de classificações terminológicas pautados em características morfológicas para climas semiáridos, visto que, a má interpretação dos termos pode alterar os resultados da pesquisa.

\begin{abstract}
:
The successive events of erosion, transport and deposition of sediments that occur in rivers provide the formation and evolution of morphological features in the channel and in the floodplain, with morphological features recurring to the region where it is inserted. Although there are studies of rivers located in the semi-arid climate, with an interlaced and anabranching pattern, mainly in Australia, there is a methodological shortage for Brazilian semi-arid rivers. The academic production on bars and islands is concentrated in fluvial environments located in tropical, subtropical and temperate climate, based on this context, the work aims to analyze the morphological characteristics of bars and islands in the river Jaguaribe-CE, a stretch that goes from the Passagem molhada of the Barragem das Pedrinhas in the municipality of Limoeiro do Norte to the wet passage of Sucurujuba in Quixeré, with time cut 2001 to 2016 (16 years). For that, the work was structured from a systemic logic, with stages of characterization of the study area; field work for photographic survey and sediment collection; laboratory stage for granulometric analysis through mechanical sieving and pipetting processes; and cabinet stage for rain and flow data collection and remote sensing and geoprocessing. The results obtained through the analysis of the orbital images showed that the main evolutionary changes regarding the growth of the area observed took place between 2014 and 2016, a period corresponding to the prolonged drought in Ceará, which began in 2012. It was found that the wider islands have a tendency to have upper lateral sedimentation, due to the flow barring that the deposit itself makes. Regarding the side bars, it was observed that their genesis is the result of distinct processes, recorded in rainy periods such as 2009 , causing the redistribution of sediment particles throughout the bed, and in dry years such as 2016, by exposure of previously submerged sandy banks that were part of the wet bed. The plain bars, in their totality, showed sand growth in $100 \%$ of the deposits, due to their resistance to erosive processes. Besides, it was considered necessary the adoption of terminological classifications based on morphological characteristics for semi-arid climates, since the misinterpretation of terms can alter the results of the research.
\end{abstract}

\section{Introdução}

Historicamente os rios tiveram papel primordial na formação e evolução das primeiras civilizações, tendo em vista sua capacidade de suprir as necessidades básicas da população, como abastecimento humano, cultivo de alimentos e criação de animais. O rio Nilo, é um grande exemplo, sendo importante para o desenvolvimento do Egito (SUGUIO; BIGARELLA, 1990).

No cenário geomorfológico, os rios também se destacam, sendo considerados os principais agentes modeladores da superfície terrestre, devido sua capacidade de erodir, transportar e depositar sedimentos. Genericamente, os rios são classificados como "cursos naturais de água doce, com canais definidos e fluxo permanente ou sazonal para um oceano, lago ou rio" (RICCOMINI et al., 2003, p. 192).

As pesquisas sobre ambientes fluviais encontram-se predominantemente inseridas em áreas de clima tropical, devido ordens de grandeza e importância no cenário mundial e nacional. Dentre os estudos sobre dinâmica fluvial em áreas semiáridas, destacam-se os trabalhos realizados na Austrália, África e América do Norte. (NANSON e CHOKE, 1992; KNIGHTON e NANSON, 1994; TOOH e NANSON, 1999).

No território brasileiro, a produção acadêmica está concentrada principalmente nas bacias do Amazonas, Paraná, Araguaia e São Francisco. No entanto, existem pesquisas pioneiras no semiárido brasileiro realizadas no Estado do Ceará, no âmbito dos processos hidrossedimentológicos da bacia do Jaguaribe. A exemplo destacam-se os trabalhos de Cavalcante et al., 2001, 2012; Costa, 2009; Bezerra, 2010; Andrade, 2016 e Queiroz et al., 2018.

A dinâmica sedimentar dos rios propicia a criação e o desenvolvimento de depósitos sedimentares, como as barras e ilhas. Tais feições, são formadas a partir de sucessivos eventos erosivos e sedimentares, de ordem natural ou antrópica. A área de estudo que se encontra inserida no clima semiárido pode gerar um comportamento de evolução morfológica diferente, uma vez que existe concentração de chuva em poucos meses do ano, e um longo período de escassez. 
Para além da influência climática, o rio Jaguaribe, objeto de estudo da pesquisa, é referência no processo de perenização de rios semiáridos pela construção de açudes (Orós e Castanhão) e passagens molhadas. Tais estruturas podem também impactar na criação e evolução dos depósitos sedimentares, uma vez que controlam e/ou alteram fluxo do rio.

O estudo das barras e ilhas, numa perceptiva temporal, pode permitir a compreensão do comportamento sedimentar dos rios semiárido, uma vez que as feições funcionam como "demarcações" históricas das mudanças de curso entre períodos secos e chuvosos, além de permitir a previsão de cenários futuros, para prevenção de impactos negativos no canal.

Baseado nessa discussão, o trabalho tem como objetivo geral analisar as características morfológicas de barras e ilhas no Rio Jaguaribe, no seu baixo curso, precisamente no trecho que vai da barragem das Pedrinhas, em Limoeiro do Norte, até a passagem molhada de Sucurujuba, em Quixeré.

Dentre os objetivos específicos destacam-se: identificar e mapear as feições morfológicas no trecho em estudo; verificar as mudanças ocorridas nas barras e ilhas referentes à morfologia, localização e capacidade de fixação; correla- cionar às alterações observadas nas feições morfológicas com os fatores naturais e antrópicos; contribuir com os estudos de dinâmica fluvial em regiões semiáridas.

\section{Métodos}

A pesquisa teve como base metodológica a análise sistêmica, com proposta de estudo interativo entre os diferentes condicionantes naturais e antrópicos que interferem nos processos erosivos e deposicionais das barras e ilhas. $\mathrm{O}$ trabalho estruturou-se nas seguintes etapas: revisão bibliográfica; caracterização da área de estudo; processo de triagem; trabalho de campo; etapa de laboratório e etapa de gabinete.

\subsection{Localização da área de estudo}

Aárea pesquisada localiza-se na sub-bacia do Baixo Jaguaribe, precisamente no canal direito do rio Jaguaribe (rio Quixeré), bifurcação direita do rio, no Município de Tabuleiro do Norte. Corresponde, especificamente, ao trecho que vai da passagem molhada da barragem das pedrinhas, no Município de Limoeiro do Norte, até a passagem molhada de Sucurujuba, em Quixeré, recobrindo uma área de aproximadamente $30 \mathrm{~km}$ de extensão (Figura 1).

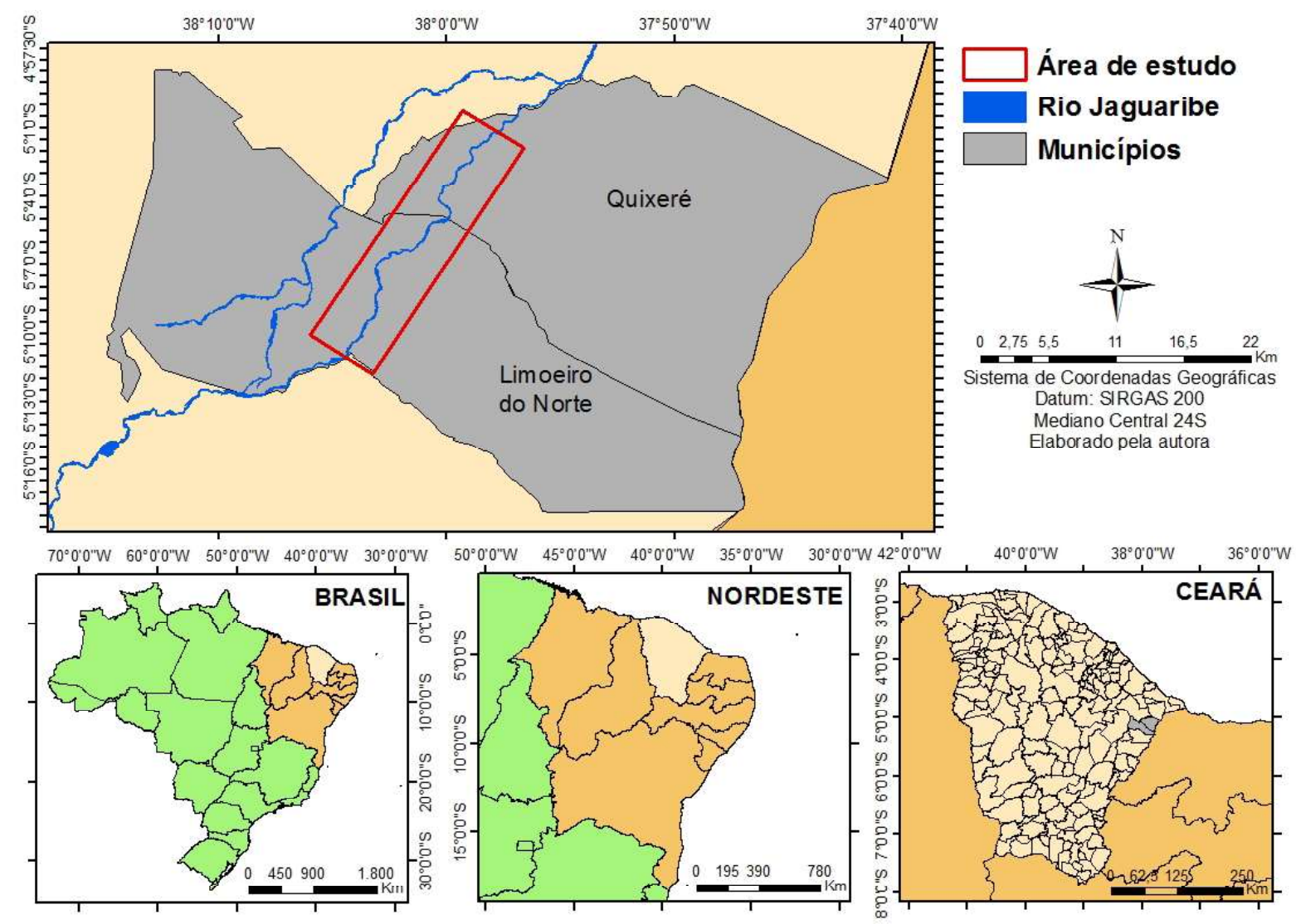

Figura 1 - Recorte da área de pesquisa, que vai de Limoeiro do Norte a Quixeré. Fonte: elaborado pela autora (2020). 


\subsection{Processo de Triagem}

A dinâmica do rio Jaguaribe proporciona um ciclo de vida curto dos depósitos devido a rápida mobilidade dos sedimentos entre períodos secos e chuvosos, típico de rios inseridos em climas semiáridos (QUEIROZ et al., 2018). Baseado nesta constatação, optou-se pela escolha de depósitos sedimentares mais estáveis, para não prejudicar a análise das feições numa perspectiva temporal de maior escala.
Os critérios para a escolha das feições foram pautados, primeiramente, na disponibilidade de fotografias áreas, segundo, pela facilidade de acesso ao local de realização do trabalho de campo. Por último, foram escolhidos depósitos com características morfológicas diferentes, para dar uma visão mais geral dos tipos de feições encontradas na área de estudo. Baseado nesses critérios, foram escolhidas 10 feições para análise, onde 4 se caracterizavam como ilhas, 4 como barras laterais e 2 como Barras de Planície (figura 2).
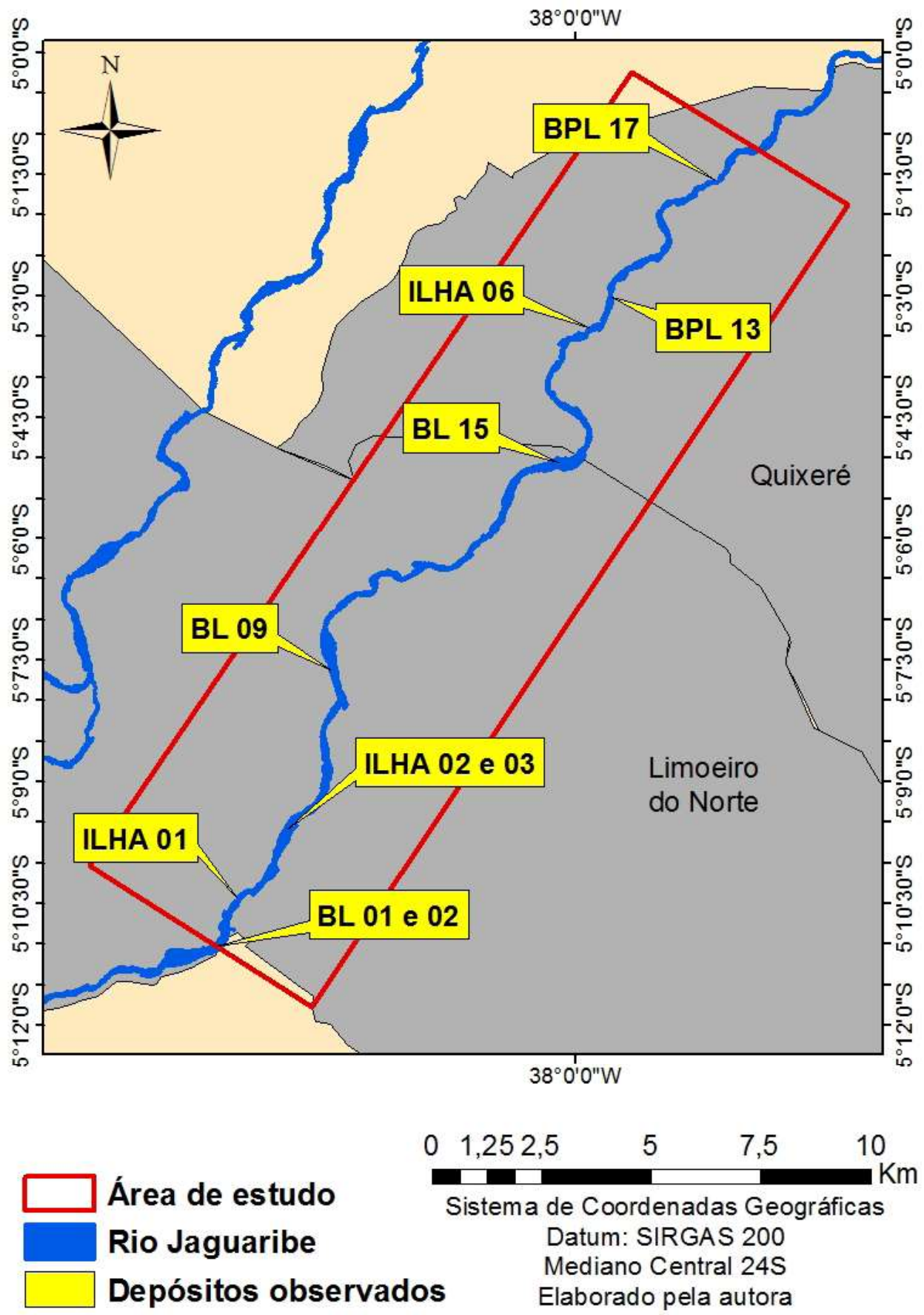

Figura 2 - Espacialização das barras e ilhas na área de estudo. Fonte: elaborado pela autora (2020). 
Para complementar da pesquisa, foram realizadas medições areais com ferramentas do Google Earth Pro para todas as barras e ilhas dentro do trecho estudado, a fim de gerar uma tabela com dados que mostrassem índices de crescimento lateral dos depósitos.

O critério de escolha dos anos de análise se deu pela própria disponibilidade de imagens de satélite do Google Earth Pro para o trecho estudado. Visando uma padronização entre os anos com registros de alta qualidade, foram escolhidas as imagens de 2001, 2009, 2011, 2014 e 2016 (intervalo de 16 anos), para análise das características morfológicas e evolutivas dos depósitos. No entanto, as alterações visualizadas entre 2014 e 2016 ganharam maior atenção no estudo, por serem considerados anos de seca prolongada no Ceará, e por isso, poderiam ter mudanças mais visíveis.

Foram também trabalhadas fotografias aéreas de 1958 e 1988 (intervalo de 30 anos), com a proposta de para considerar a perspectiva histórica do comportamento hidrossedimentar do rio Jaguaribe antes da política de açudagem no Ceará (1958), e no seu início (1988). Seria então possível comparar, ainda que de maneira superficial, a influência na morfologia dos depósitos, uma vez que o controle de vazão age diretamente sobre os processos de erosão, transporte e deposição de sedimentos.

\subsection{Etapa de campo}

Foram realizados levantamentos fotográficos das feições, coletas de sedimentos dos depósitos e do leito fluvial, utilizando pá pequena e sacos plásticos transparentes. Por sim, foram feitas anotações gerais sobre as características das barras e ilhas, considerando a vegetação presente (herbácea, arbustiva ou arbórea) no depósito, sua morfologia e o uso e ocupação da área.

Para compreender a influência das passagens molhadas na dinâmica das feições morfológicas, foi de interesse estratégico do estudo a escolha de pontos de coleta localizados em um raio de, no máximo, $1 \mathrm{~km}$ (montante ou jusante) de distância dos barramentos.

Considerando os inúmeros episódios erosivos e deposicionais que as barras e ilhas sofreram no processo de formação e evolução, a granulometria do material presente pode encontrar-se variável, sendo necessária à coleta de amostras em pontos diferentes para uma caracterização mais geral e completa.

\subsection{Etapa de laboratório}

$\mathrm{Na}$ etapa de laboratório os sedimentos coletados em campo foram diferenciados pela sua consistência granulométrica, sendo separados entre finos e grosseiros. Essa distinção é normalmente feita a partir do limite de $1 / 16 \mathrm{~mm}(0,062 \mathrm{~mm})$ de diâmetro do grão. Este limite pode ser diferente para alguns trabalhos específicos como aqueles relacionados à geologia aplicada, à engenharia civil ou trabalhos de pedologia (SUGUIO, 1973).

Vários tipos de técnicas são utilizados nas análises de sedimentos, no entanto, o processo de peneiramento mecânico (material grosseiro) e de pipetagem (material fino) continuam sendo mais utilizados devido à simplicidade de operação e menor custo dos equipamentos requeridos.

Segundo Suguio (1973) o processo de peneiramento mecânico permanece até hoje como método praticamente universal e absoluto na análise das frações arenosas (material de maior granulometria).

Os sedimentos com diâmetro menor que $1 / 16 \mathrm{~mm}$ $(0,062)$ diferentemente das partículas maiores (areias e seixos) que decantam sob condições de inércia, possuem mais técnicas de análise devido à complexidade do processo de decantação (material siltoso e argilosos) que acontece sob condições de resistência viscosa (SUGUIO, 1973). Entre os processos relacionados à Lei de decantação das partículas mais finas está a técnica de pipetagem baseada na lei de Stokes.

Para realizar a técnica de peneiramento mecânico foram utilizadas 12 peneiras com os seguintes diâmetros: 2,8 / 2,0 / 1,4 / 1,0 / 0,710 / 0,500 / 0,350 / 0,250 / 0,180 / 0,125 / 0,090 / 0,062 (Figura 3). A quantidade em gramas de sedimentos a ser utilizado para análise é dada em função do tipo granulométrico do material. Suguio (1973) recomenda o uso de $100 \mathrm{~g}$ para peneiramento de areia. À medida que aumenta o tamanho dos grãos há maior necessidade de sedimentos para serem peneirados. Como o material coletado nas feições eram aparentemente constituídas por areia, silte e argila, utilizou-se $100 \mathrm{~g}$ da amostra coletada.

Depois de secadas em estufa por 24 horas há 50 $\mathrm{C}^{\circ}$, as amostras foram lavadas em peneira de diâmetro $0,062 \mathrm{~mm}$, no intuito de separar o material grosso do material fino. O sedimento que ficou contido na peneira (grosseiro) foi coletado e colocado novamente na estufa para secagem por 24 horas há $50 \mathrm{C}^{\circ}$. Depois de secas, as amostras foram alocadas no jogo de peneiras e levadas ao agitador para separação. 


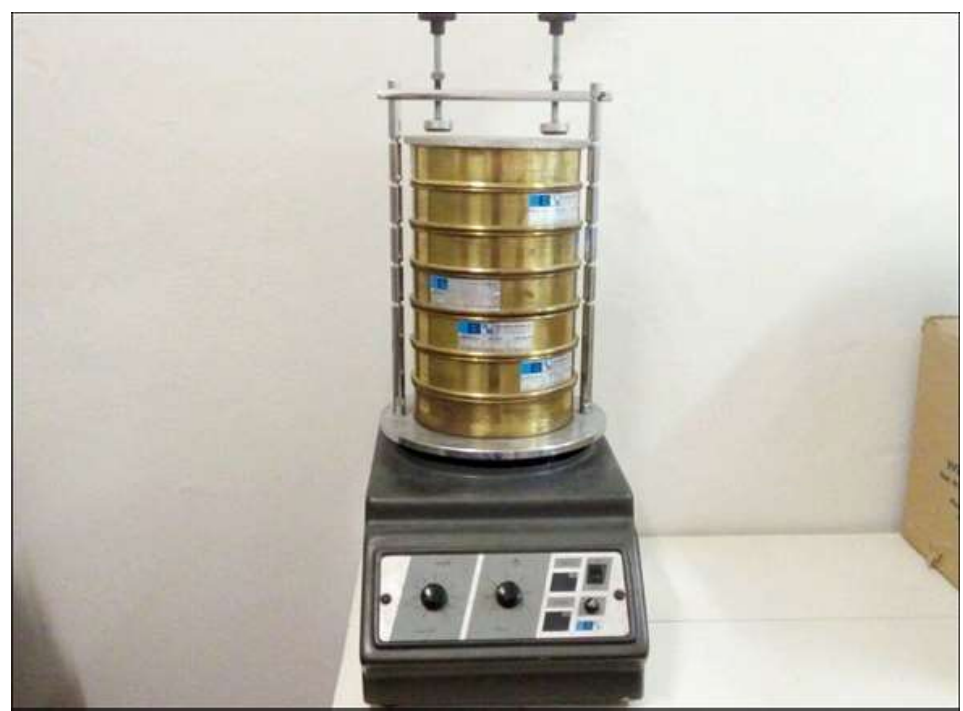

Figura 3 - Processo de Peneiramento mecânico, técnica destinada para material com granulometria grosseira. Fonte: acervo da autora (2018).

O tempo de agitação foi estipulado em 10 minutos. Feito isso, foi pesada a quantidade de sedimentos contidos em cada peneira, utilizando para este procedimento uma balança de precisão e ficha de análise granulométrica para o registro dos dados.

O material que passou pela peneira de $0,062 \mathrm{~mm}$ durante a lavagem da amostra com material fino foi colocado em baldes para em seguida ser submetido aos processos de pipetagem no laboratório de química da FAFIDAM.

Este método, segundo Suguio (1973, p.53),

[...] é baseado nas mudanças de concentração de partículas em uma suspensão originalmen- te uniforme, pela tomada de várias amostras com uma pipeta (em intervalos de tempo definido), em profundidades que corresponde à do material que acabara de sedimentar naquele momento [...].

Os sedimentos finos contidos nos baldes passaram por um processo de decantação, que durava em média uma semana. Após a sedimentação de todo o material para o fundo do balde, foi feito a transferência para uma proveta de $1000 \mathrm{ml}$ onde foi homogeneizado (Figura 12). A solução contida na proveta foi coletada por uma pipeta, baseada em intervalos de tempo e profundidades padrões, conforme a granulação do material.

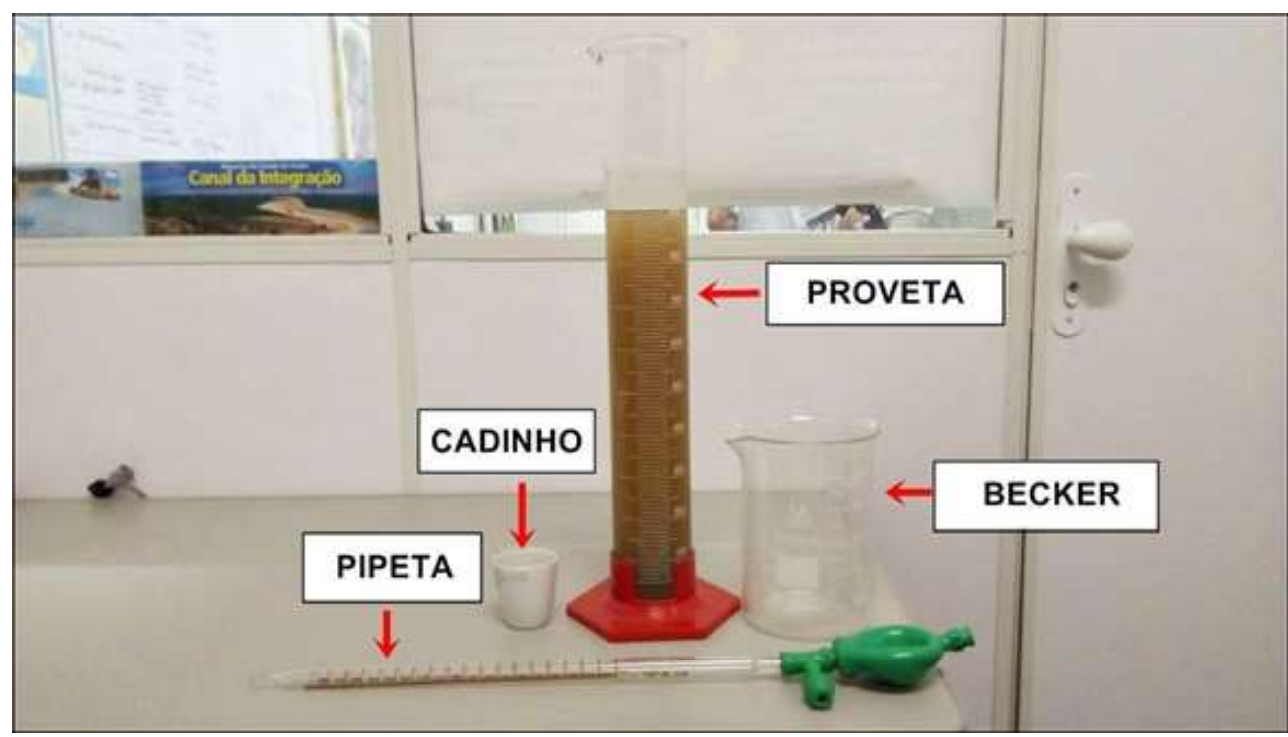

Figura 4 - Vidrarias utilizadas para a pipetagem, técnica usada para material fino. Fonte: acervo da autora (2018). 
O material pipetado foi em seguida depositado em cadinhos (pesados anteriormente) baseado no tempo de decantação das partículas, conforme a tabela 1. Dada a alta taxa de decantação das partículas, foram feitas apenas 5 coletas.

Os cadinhos com o material pipetado foram colocados na estufa para evaporação da água presente na amostra. Logo depois, foram submetidos à pesagem para calcular a quantidade de material fino contido neles, sendo determinado pela diferença de peso entre o cadinho com a amostra e o cadinho vazio. Após os procedimentos descritos, foram realizados cálculos estatísticos com os dados colhidos para definição percentual do padrão majoritário de composição granulométrica, isto é, qual tipo de material estava mais presente na amostra baseado na classificação dos solos da ABNT NBR 6502/95.

Tabela 1: Tempos, profundidades e granulações para análise granulométrica por pipetagem.

\begin{tabular}{cccccc}
\hline Tipo de material & Diâmetro $(\mathbf{m m})$ & Profundidade & H & Min & $\mathbf{S}$ \\
\hline Areia muito fina & $1 / 16(0,062)$ & 20 & 0 & 0 & 58 \\
Silte grosso & $1 / 32(0,031)$ & 10 & 0 & 3 & 52 \\
Silte médio & $1 / 640,016$ & 10 & 0 & 7 & 44 \\
Silte fino & $1 / 1280,008$ & 10 & 0 & 31 & 0 \\
Silte muito fino & $1 / 2560,004$ & 10 & 2 & 3 & 0 \\
Argila & $1 / 5120,002$ & 10 & 8 & 10 & - \\
Argila & $1 / 10240,001$ & 5 & 6 & 21 & - \\
Argila & $1 / 20480,0005$ & 5 & 5 & 25 & - \\
\hline
\end{tabular}

Fonte: SUGUIO, 1973, p. 54.

\subsection{Etapa de gabinete}

Foram realizadas aquisições de dados referentes às precipitações e vazões registradas entre 2001 e 2016. Para isso foram coletados dados das estações pluviométricas (00538069) e fluviométricas (36390000) do Peixe Gordo, monitoradas pela Agência Nacional de Água (ANA), localizadas no Município de Tabuleiro do Norte (15 km a montante da área de estudo). Estas foram escolhidas como base do estudo por serem séries históricas longas e completas. As informações foram adquirias através do Sistema de Informações Hidrológicas (HIDROWEB), disponíveis no endereço eletrônico: http://www.snirh.gov.br/hidroweb/.

Para a manipulação dos dados foi utilizado o software Hidro 1.3, desenvolvido pela Agência Nacional de Águas, proporcionando a análise dos dados através da geração de gráficos e cruzamento de informações (pluviométricas x fluviométricas). Para tal, foram utilizados dados correspondentes à soma total das chuvas precipitadas no ano e a média de vazão mensal.

Ainda na etapa de gabinete, foram utilizadas ferramentas de geoprocessamento e sensoriamento remoto, para auxiliar a compreensão do comportamento evolutivo das barras, além de identificar e classifica-las com base nas características morfológicas e de localização. Atividades como, reconhecimento de campo, caracte- rização da área de estudo, mapeamento dos depósitos, criação de mapas e bancos de dados, só foram possíveis através da utilização dos softwares: ArcGis 10.5, Qgis 2.18 e Google Earth Pro.

O ArcGis 10.5 e Qgis 2.18 compõem um conjunto integrado de softwares de Sistema de Informação Geográfica (SIG) que fornece ferramentas baseadas em padrões para realização de análise espacial, armazenamento, manipulação, processamento de dados geográficos e mapeamento. Já o Google Earth Pro é uma ferramenta de geoprocessamento cedida gratuitamente pela empresa Google. Sua interface apresentada em um modelo tridimensional do globo terrestre, é gerada a partir de mosaicos de imagens de satélite obtidas de fontes diversas (imagens aéreas e GIS 3D).

Com o auxílio das imagens do Google Earth Pro, foi possível realizar um estudo prévio para escolha das feições, além de quantificar e classificar os tipos de depósitos encontrados no trecho, dispondo de imagens entre 2001 e 2016. Posteriormente, foi feito o georeferenciamento das imagens de satélite com o Qgis 2.18 , com a ferramenta "georreferenciador" devido à facilidade de acesso (gratuito), e de manipulação.

O software Arc Gis 10.5, foi utilizado para o mapeamento morfológico das barras e ilhas, assim como, para criação de mapas, com o uso da ferramenta ArcMap 10.5. 
Foram utilizadas fotografias aéreas de 1958 e 1988, cedidas pelo INCRA e IDACE, respectivamente, e imagens de satélite do Google Earth Pro, do ano de 2001 a 2016.

\section{Resultados e Discussão}

Considerando o pressuposto de que os depósitos sedimentares refletem o ajuste das condições de fluxo e do transporte de sedimentos, a pesquisa procurou recobrir anos secos, chuvosos e com precipitações ha- bituais, avaliando os dados históricos de médias anuais e mensais de pluviometria e vazão.

A precipitação é um fator meteorológico que apresenta grande influência na dinâmica hidrossedimentar dos rios do semiárido brasileiro, uma vez que impulsiona a ação dos processos erosivos, proporcionando a redistribuição de sedimentos por todo o leito. Os dados históricos coletados, correspondem à distribuição anual das precipitações registrada na estação de Peixe Gordo (00538069) entre os anos de 2001 e 2016 (figura 5).

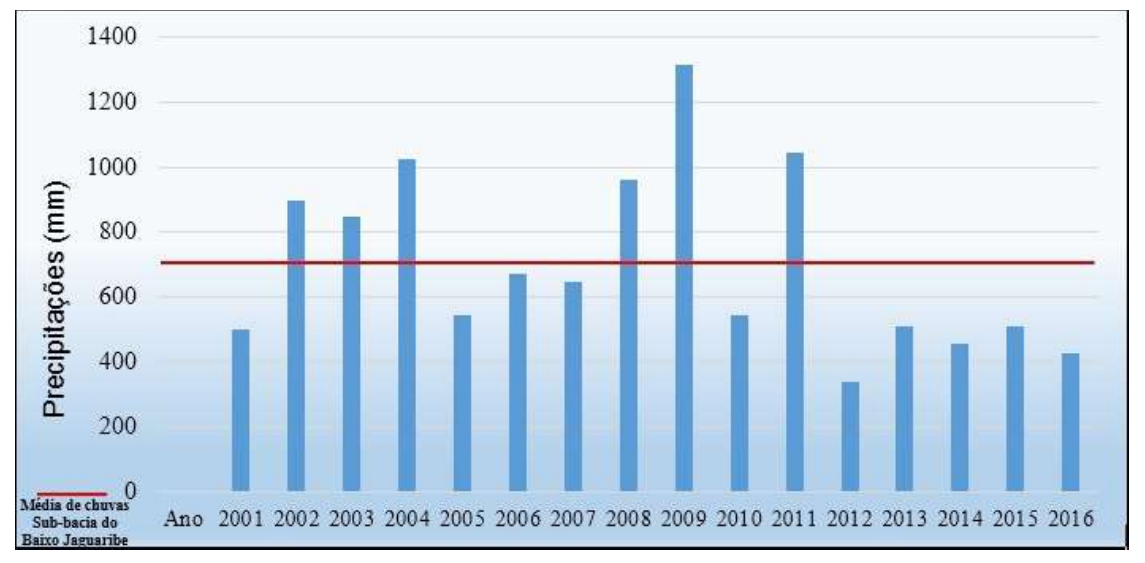

Figura 5 - Gráfico de precipitação da sub-bacia do baixo Jaguaribe. Fonte: HIDROWEB - ANA, 2018. Dados organizados pela autora.

Tendo como base a média de precipitação da sub-bacia do baixo Jaguaribe de 704,5mm/ano, o ano 2001 é caracterizando como seco, cuja precipitação total foi de 501,5 mm. Já em 2009, considerado ano muito chuvoso, os registros disparam, chegando até $1.313,8$ $\mathrm{mm}$. O ano de 2011 se caracterizou como o último ano chuvoso antes da seca prolongada, com 1.047,8 mm. Posteriormente, é possível perceber uma diminuição brusca nas precipitações entre 2012 e 2016, que corres- ponde ao período de seca no Ceará, registrando chuvas com média de 450,3 mm/ano.

A vazão do rio está diretamente ligada à precipitação, obedecendo a um padrão semelhante de variação, ou seja, anos chuvosos geralmente correspondem a momentos de maior energia no canal, assim como o inverso. A figura 6, mostra a distribuição média mensal das vazões registradas na série histórica da estação de Peixe Gordo (36390000), entre os anos de 2001 a 2016.



Figura 6 - Gráfico de vazão da sub-bacia do baixo Jaguaribe. Fonte: HIDROWEB - ANA, 2018. Dados organizados pela autora. 
Os anos de 2004, 2008 e 2009, registraram a maior energia no canal considerando os 16 anos de análise, com destaque para o último, que chegou a uma média mensal de aproximadamente $1.600 \mathrm{~m}^{3} \mathrm{~s}$. Os dados registrados de 2012 a 2016 (período de seca) possuem média de $9,5 \mathrm{~m}^{3} \mathrm{~s}$ mensal, chegando a marcar cerca de 2,0 $\mathrm{m}^{3} \mathrm{~s}$ em 2016.

Mesmo que a vazão obedeça a padrões estatísticos semelhantes à pluviometria, é válido ressaltar que rios perenizados podem, por vezes, manter o controle da vazão em períodos chuvosos, ou liberar mais água em anos de seca, tudo vai depender dos interesses socioeconômicos e ambientais da região. Como exemplo, o ano de 2011 teve precipitações acima da média $(1.047,8 \mathrm{~mm})$, mas sua vazão registrou $25,1 \mathrm{~m}^{3} \mathrm{~s}$, ao passo que em 2004 as chuvas foram semelhantes (1026,2 mm), mas a vazão média foi de $86,7 \mathrm{~m}^{3} \mathrm{~s}$, ou seja, bem superior ao ano anterior.

Considerando a influência da energia de fluxo para a formação e evolução dos depósitos sedimentares, Queiroz et al., (2018), afirmam que a variação na quantidade total de barras, de um ano para outro, se modifica a medida que a pluviometria e a vazão oscilam. Portanto, índices elevados de vazão aumentam a competência do rio, transportando maior quantidade de sedimentos para formação de nova feição. Já as baixas vazões, contribuem para o a fixação e crescimento lateral dos depósitos já formados.

A análise inicial das imagens de satélite, disponíveis entre 2001 a 2016, revelaram que as principais mudanças evolutivas (crescimento lateral) aconteceram entre 2014 e 2016, período de seca prolongada no Ceará. (Tabela 2).

Tabela 2: Processo evolutivo de sedimentação lateral das barras e ilhas entre os anos de 2014 e 2016.

\begin{tabular}{c|c|c|c|c}
\hline $\begin{array}{c}\text { Depósitos } \\
\text { sedimentares }\end{array}$ & $\left.\mathbf{2 0 1 4} \mathbf{( m}^{\mathbf{2}}\right)$ & $\mathbf{2 0 1 6}\left(\mathbf{m}^{\mathbf{2}}\right)$ & $\begin{array}{c}\text { Crescimento Areal } \\
(\mathbf{2 0 1 4 - 2 0 1 6 )}\end{array}$ & $\begin{array}{c}\text { Percentual de crescimento } \\
(\mathbf{2 0 1 4 - 2 0 1 6 )}\end{array}$ \\
\hline ILHA 01 & 31.368 & 45.986 & 14.618 & $46,6 \%$ \\
ILHA 02 & 18.402 & 19.750 & 1.348 & $7,3 \%$ \\
ILHA 03 & 53.354 & 55.427 & 2.073 & $3,9 \%$ \\
ILHA 06 & 7.222 & 14.515 & 7.293 & $100,1 \%$ \\
BL 01 & 7.060 & 11.773 & 4.713 & $66,8 \%$ \\
BL 02 & 0 & 16.036 & 16.036 & - \\
BL 09 & 3.132 & 13.183 & 10.051 & $320,9 \%$ \\
BL 15 & 19.614 & 24.448 & 4.834 & $24 \%$ \\
BPL 13 & 122.698 & 148.694 & 25.996 & $21 \%$ \\
BPL 17 & 116.685 & 201.279 & 84.594 & $73,5 \%$ \\
\hline
\end{tabular}

Fonte: Elaborado pela autora (COELHO, 2018).

Foi observado que dentre os 10 depósitos, todos sofreram processo de sedimentação lateral. No entanto, a ação se deu de maneira distinta, em decorrência da interação de agentes naturais (pluviometria e vazão) e antrópicos (introdução de barramentos).

\subsection{Caracterização de ilhas}

Dentre todos os depósitos observados na área de estudo, 06 se caracterizavam como ilhas. Essas ilhas foram escolhidas baseado em padrões de localização (centro do canal), fixação (presença de vegetação) e comprimento ( $\geq$ $200 \mathrm{~m}$ ). Embora todas as ilhas mapeadas tenham sofrido processo de sedimentação lateral ou crescimento areal, esse ocorreu de maneira distinta de uma para outra, em detrimento das diferenças morfológicas.

As Ilhas mais largas, como a ilha 01 , possuem tendências de sedimentação lateral superior a ilhas mais compridas, em decorrência do próprio barramento de fluxo da feição, criando "zonas de sombra" (FERNANDEZ, 1993; SANTOS, 1992). Isto é, áreas de baixa, energia onde a velocidade da corrente é menor, ficam propensas a criação de barras de soldamento (Figura 7).

No ano de 2014 a ilha recobria uma área de aproximadamente $31.368 \mathrm{~m}^{2}$, ao passo que, em 2016 a feição passou a ocupar uma área de $45.986 \mathrm{~m}^{2}$, evidenciando um amento de 46,6\%. O crescimento areal da ilha é resultado da junção entre os baixos índices pluviométricos registrados no período de seca, com média total de chuvas de 450,3 mm entre 2012 e 2016, além de baixas vazões com médias de $10,9 \mathrm{~m}^{3} \mathrm{~s}$ e pelo crescimento vegetativo (herbáceo, arbustivo e arbóreo) nas feições, que acelerou a deposição nas zonas de sombra, unindo às barras de soldamento a ilha. 

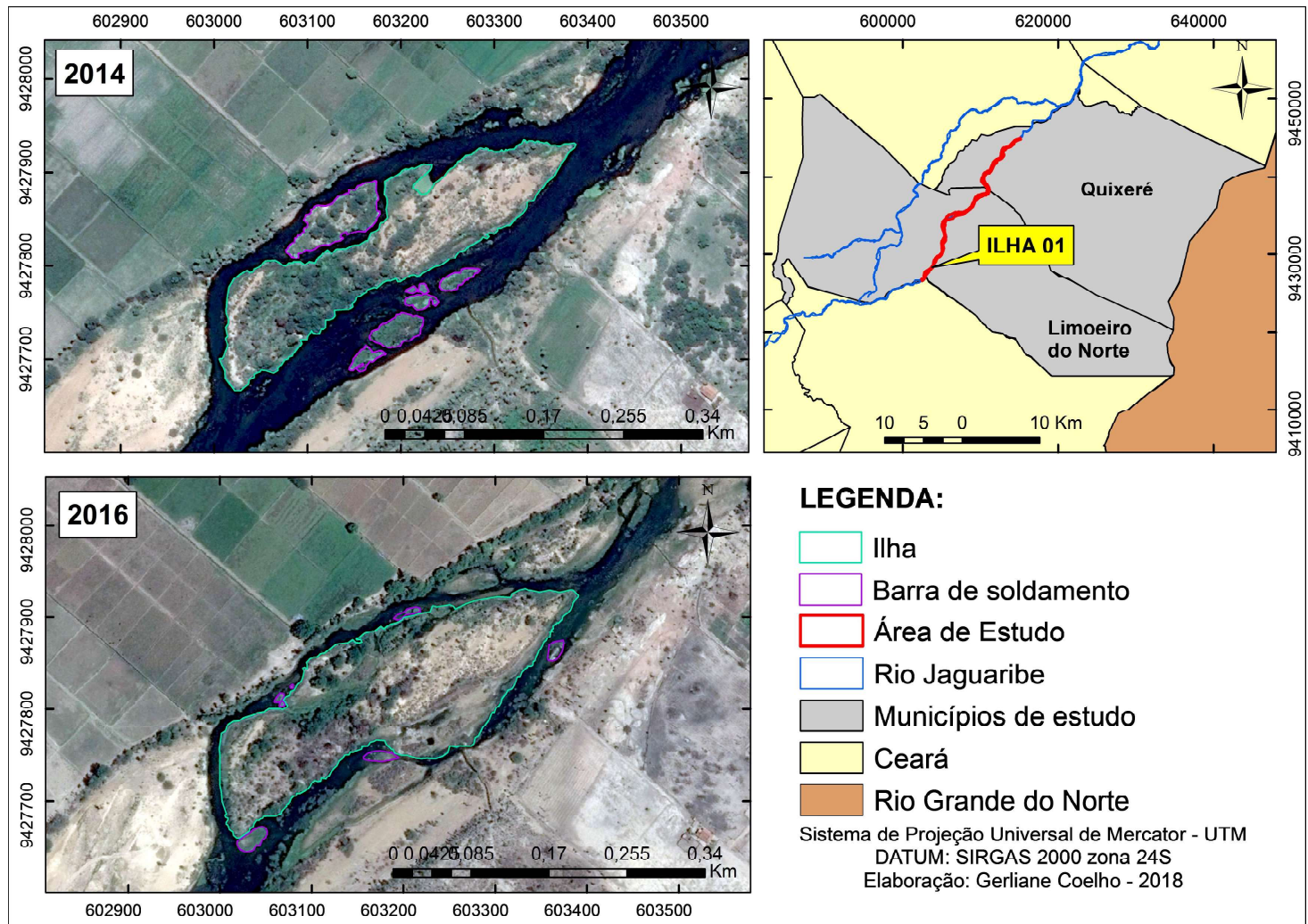

LEGENDA:

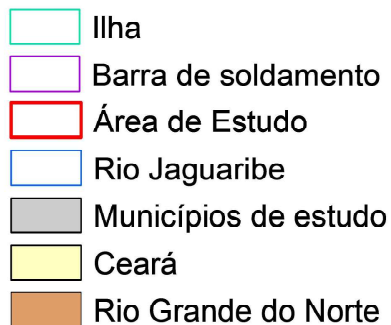

Sistema de Projecão Universal de Mercator - UTM DATUM: SIRGAS 2000 zona $24 S$ Elaboração: Gerliane Coelho - 2018

Figura 7 - Processo de soldamento das barras de coalescência com a "ilha 01", localizado em Limoeiro do Norte-CE. Fonte: elaborado pela autora (2018).

As imagens de satélite, de 2014, foram retiradas no mês de março, período com registro de chuvas de 112 $\mathrm{mm}$ e vazões de $17,31 \mathrm{~m}^{3} \mathrm{~s}$, ao passo que, em 2016, as chuvas eram de $16 \mathrm{~mm}$ e vazão de $3,35 \mathrm{~m}^{3} \mathrm{~s}$ em dezembro. Como a distribuição de chuvas no Ceará acontece em poucos meses do ano, a data de registro da imagem pode mostrar realidades distintas. Embora 2014 seja um ano de seca, a pluviometria e vazão registradas são superiores a 2016, demonstrando que o "crescimento" do depósito na verdade é uma diminuição do leito molhado.

Cenários futuros de escassez indicam à possibilidade de soldamento da ilha a margem esquerda do canal (Figura 8), que posteriormente entraria na classificação como barra de planície. Justifica-se a hipótese, com base na visualização em campo da baixa energia de fluxo e profundidade da parte esquerda da bifurcação feita pela ilha. Segundo Costa (2009), em decorrência da diminuição da força das águas, aumenta-se o risco de entalhe do rio por materiais grosseiros, isto é, o canal possuiria tendências de assoreamento.

A junção dos processos naturais de sedimentação com a ação antrópica observadas nas proximidades do rio, como a ocupação irregular e a retirada de areia das barras de planície e dentro do próprio leito menor pela capitação de água, pode acelerar ainda mais o processo de assoreamento.

A composição granulométrica da ilha 01 foi verificada em três pontos. A primeira amostra foi coletada na parte montante do depósito, com sedimentos entre areia Média (39,9\%) e Grossa (28,7\%). A segunda coleta foi estrategicamente feita na área, que em 2014, se caracterizava como um corredor entre a ilha e a barra de soldamento esquerda, tendo predominância de areia média $(53,4 \%)$ e fina $(21,4 \%)$. O último dado coletado correspondia ao sedimento de leito, com variação entre areia média (46,9\%) e Grossa (29,3\%).

As amostras granulométricas são compostas, em grande parte, por areia média (até mesmo no leito), um pouco abaixo da média para rios semiáridos, o que pode ser resultado do barramento de parte do suprimento dendrítico mais grosseiro, pela passagem molhada da barragem das pedrinhas em Limoeiro do Norte, visto que, a ilha 01 está localizada a cerca de 500 metros a jusante da passagem molhada. Alguns estudos afirmam que a carga de sedimentos pode ser reduzida até cerca de $90 \%$ a jusante do rio represado (GUERRA; CUNHA, 1994). 




Figura 8 - Trecho localizado entre a "ilha 01" e a margem esquerda do canal. Fonte: acervo da autora (2018).

As ilhas 02 e 03 , situadas $1 \mathrm{~km}$ a jusante da ilha 01 possuem diferenças morfológicas, no qual, os dois depósitos têm características alongadas, com estreitamento lateral, registrando cerca de $890 \mathrm{~m}$ de comprimento na ilha 03, o que proporcionaram eventos erosivos e sedimentares diferentes daqueles observados anteriormente (Figura 9).
Em 2014, as ilhas 02 e 03 recobriam uma área de $18.402 \mathrm{~m}^{2}$ e $53.354 \mathrm{~m}^{2}$, respectivamente, ao passo que, em 2016 elas mediam $19.750 \mathrm{~m}^{2}$ e $55.427 \mathrm{~m}^{2}$, indicando, em termos percentuais, um aumento de $7,3 \%$ e $3,9 \%$ em dois anos, caracterizando o menor índice de evolução areal das ilhas observadas.
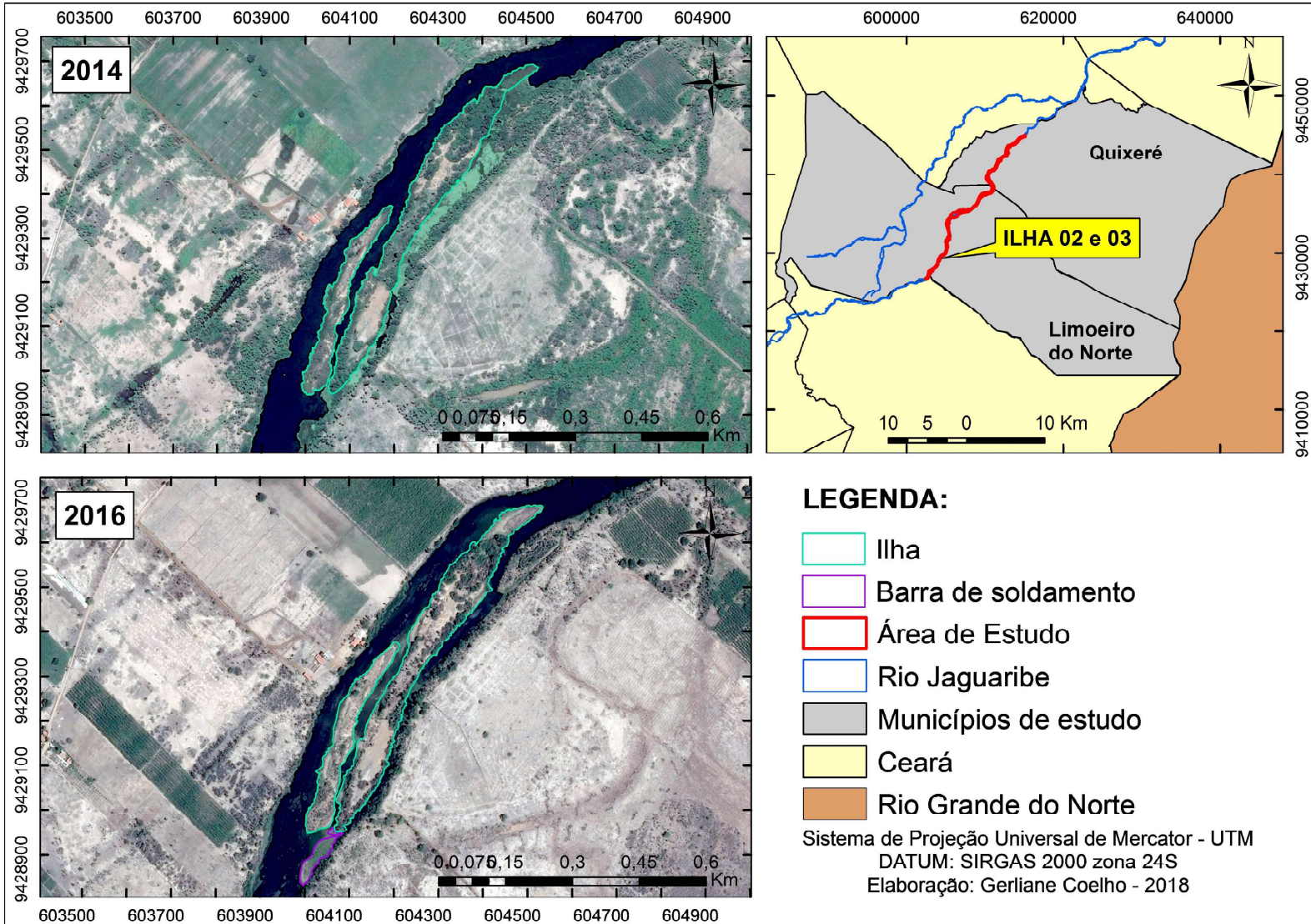

\section{LEGENDA:}

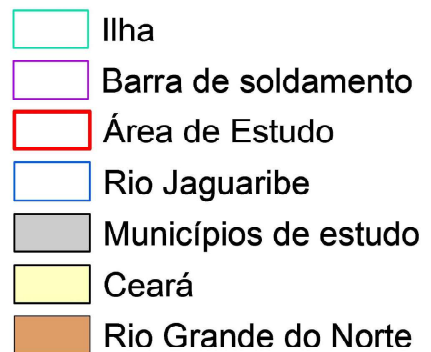

Sistema de Projeção Universal de Mercator - UTM DATUM: SIRGAS 2000 zona 24S Elaboração: Gerliane Coelho - 2018

Figura 9 - Dinâmica evolutiva de duas ilhas, localizadas em Limoeiro do Norte-CE. Fonte: elaborado pela autora (2018). 
Acredita-se que por razão da disparidade do comprimento das ilhas em relação à largura, não houve barramento de fluxo considerável, recebendo menos impactos erosivos. Por outro lado, o mesmo fator pode ter efeito reverso, uma vez que o menor barramento do fluxo diminui a incidência de zonas de sombra no trecho e, consequentemente, o desenvolvimento areal do depósito. Em resumo, acontece um equilíbrio entre os processos erosivos e deposicionais, retardando a evolução das ilhas.
Nos anos de 1958 e 1988 os cenários para as ilhas 01,02 e 03 eram diferentes dos atuais, tornando perceptível o impacto da açudagem e perenização na morfologia dos depósitos (Figura 10). O rio em 1958, possuía características de fluxo intermitente, observadas somente por recurso visual, devido à falta de registros pluviométricos. $\mathrm{O}$ ano foi considerado seco baseado em estudos de Cavalcante (2012), o que dificultava a identificação do próprio leito e dos depósitos sedimentares.

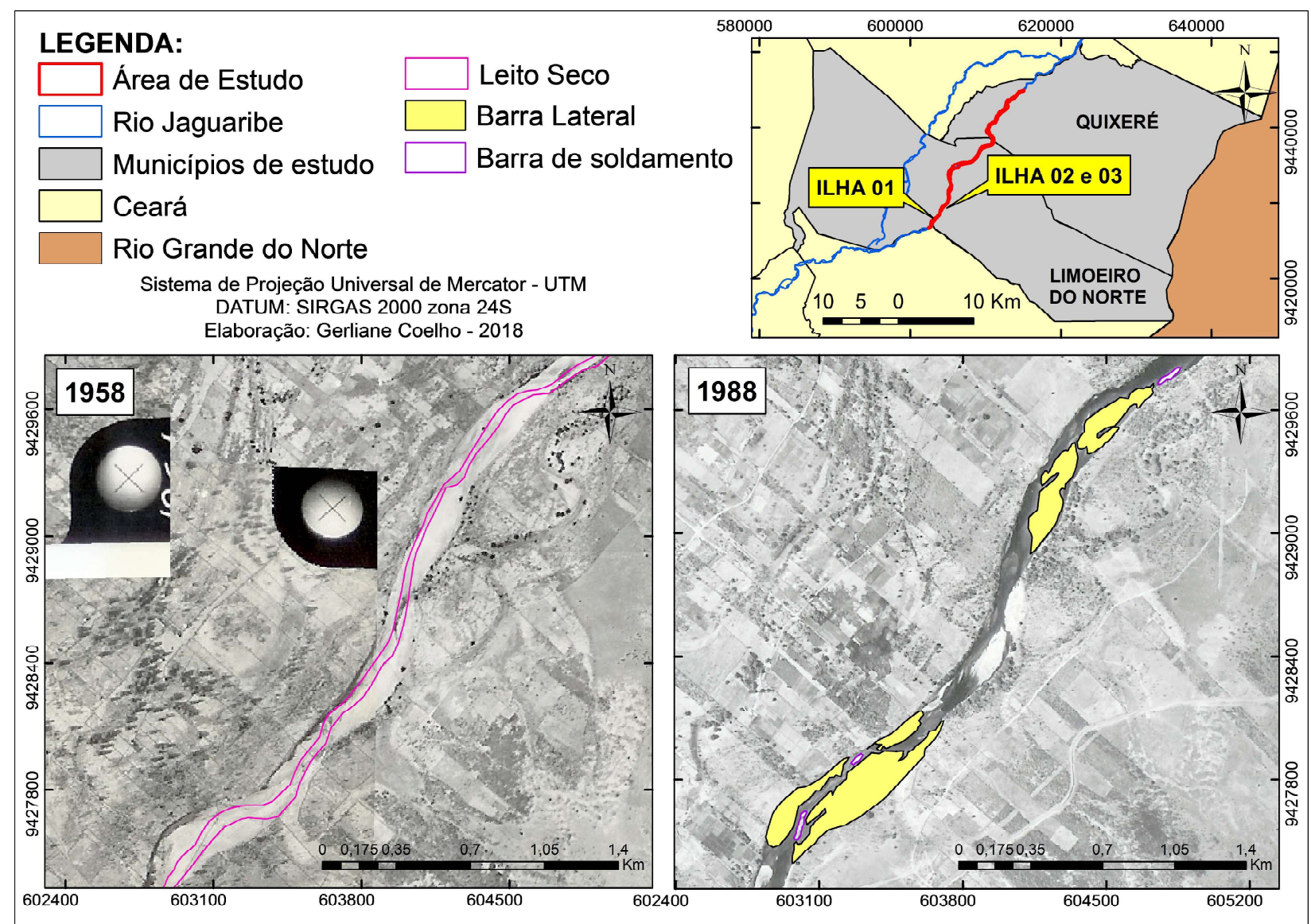

Figura 10 - Comportamento morfológico das “ilhas 01, 02 e 03 ” nos anos de 1958 e 1988. Fonte: elaborado pela autora (2018).

Após um intervalo de 30 anos entre as fotografias, as mudanças decorrentes da perenização já são visualizadas. Resultado do controle de vazão feito pelo açude Orós (1961) e pelas passagens molhadas, é registrado em 1988 um total anual pluviométrico de $891,2 \mathrm{~mm}$ e média anual de vazão de $126,4 \mathrm{~m}^{3} \mathrm{~s}$. O rio passou a apresentar leito mias regular e definido, possibilitando a caracterização das ilhas (01, 02 e 03$)$ que, no referido ano, eram classificadas como barras laterais.

Considerando a possível influência que os barramentos possuem na dinâmica sedimentar local do rio e na evolução das feições morfológicas, a ilha 06 retrata o mais visível episódio de impacto negativo no canal causado pelas passagens molhadas, no caso, a PM do Eduardo (Quixeré), localizada a cerca de $15 \mathrm{~m}$ a montante da ilha (Figura 11).

No ano de 2014, a ilha 06, recobria uma área de aproximadamente $7.222 \mathrm{~m}^{2}$, passando para $14.515 \mathrm{~m}^{2} \mathrm{em} 2016$, um crescimento areal de $100,1 \%$, obedecendo à média evolutiva do trecho estudado. Embora o desenvolvimento das ilhas tenha sido influenciado pelas baixas vazões e o soldamento de barras de coalescência, foi possível visualizar em campo a alta influência que o barramento teve no processo de fixação e desenvolvimento da ilha. 
Caracterização de Feições Morfológicas no Canal do Rio Jaguaribe: Trecho Limoeiro do Norte-Quixeré
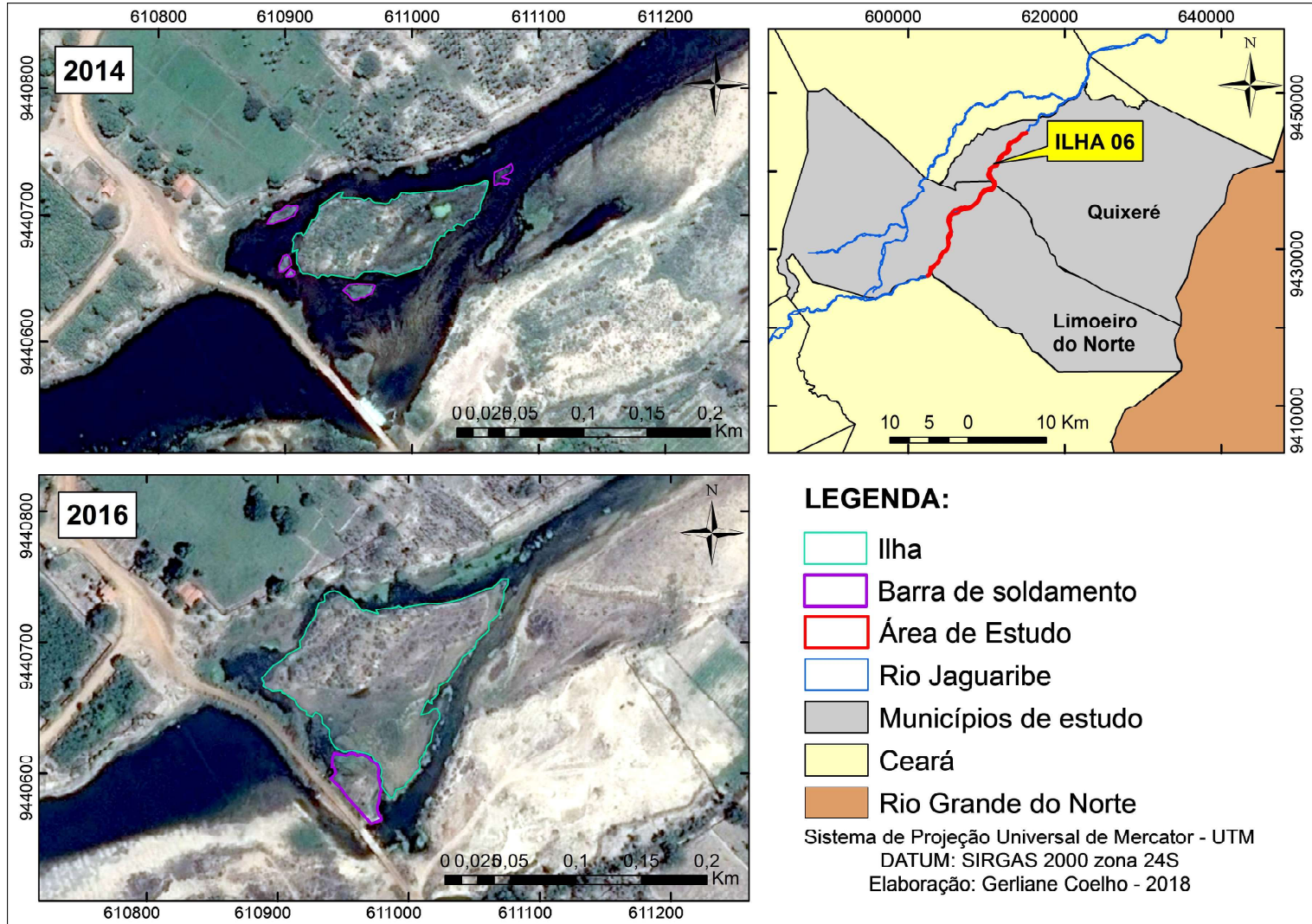

\section{LEGENDA:}

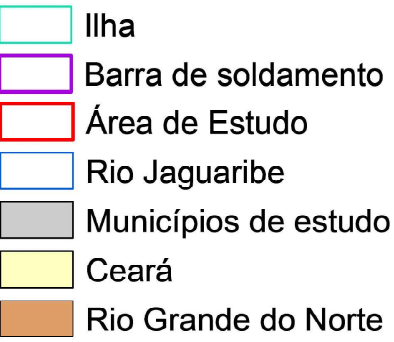

Sistema de Projeção Universal de Mercator - UTM

DATUM: SIRGAS 2000 zona 24S

Elaboração: Gerliane Coelho - 2018

Figura 11 - Ilha localizada 15 metros a jusante da passagem molhada do Eduardo, no Município de Quixeré-Ce. Fonte: elaborado pela autora (2018).

A Passagem molhada do Eduardo, foi feita com terra e restos de material de construção civil, como: tijolos, telhas e pedras (figura 12). A escolha por esse tipo de barramento se deve ao barateamento dos custos, causando impactos negativos devido à instabilidade do material em períodos de alta energia, como ocorrido em 2009 , onde as vazões registraram $1.600 \mathrm{~m}^{3} \mathrm{~s}$, destruindo parcialmente a passagem molhada.

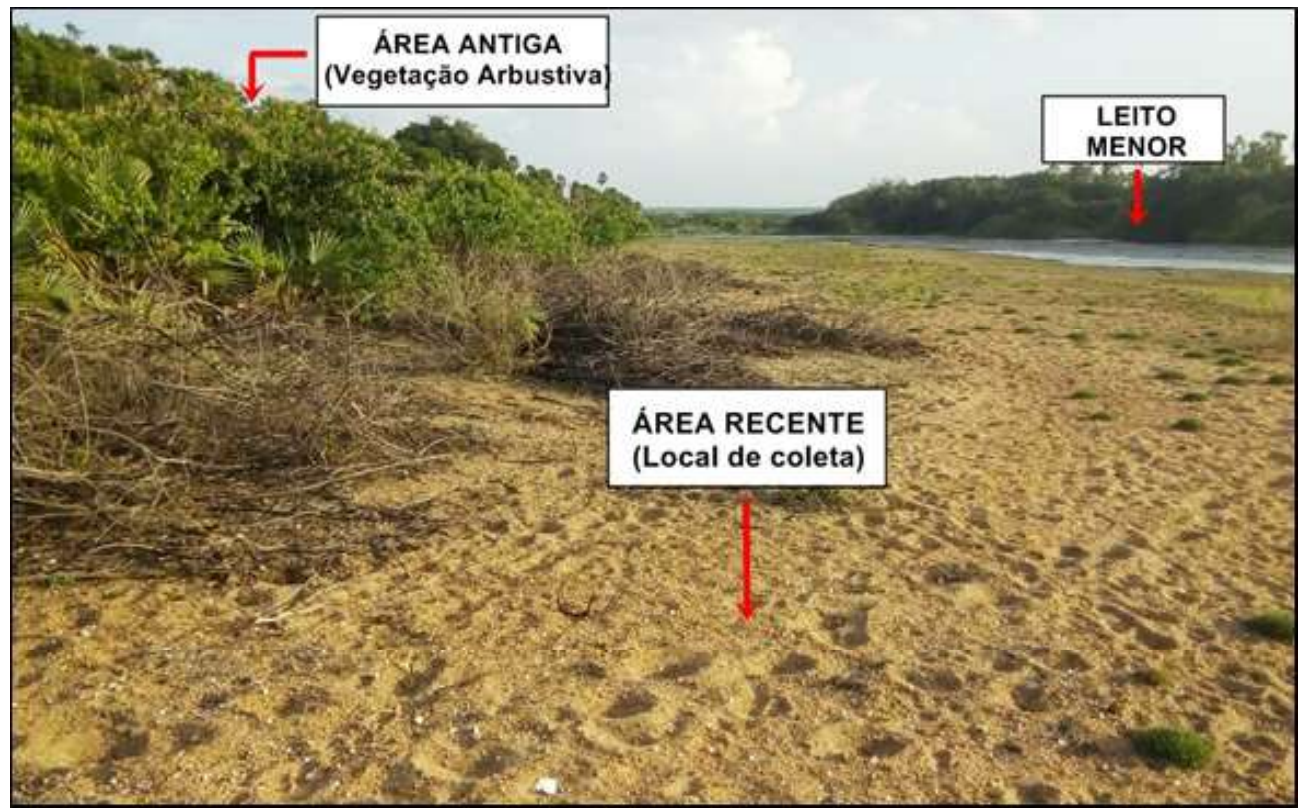

Figura 12 - Destroços da passagem molhada do Eduardo depositados na Ilha 06, no município de Quixeré-Ce. Fonte: acervo da autora (2018). 
As pedras, telhas e tijolos desprendidos da passagem molhada do Eduardo foram transportados para jusante, agregando parte do material a ilha. A análise granulométrica do depósito mostrou altas taxas de Grânulos $(51,3 \%)$ no leito, resultantes dos destroços da passagem molhada. No entanto, cerca de $40 \%$ da amostra é representado por areia média, correspondendo a granulometria natural de fundo do canal. O mesmo fato se repete na parte da Ilha sem destroços, com sedimentos variando entre areia grossa $(41,7 \%)$ e areia média $(35.5 \%)$.

O material de construção colabora com a fixação da ilha, uma vez que, aumenta a área ocupada pelo depósito sedimentar e, também, sua capacidade de resistência frente a processos erosivos. Alteram-se ainda as características granulométricas de leito, contribuindo para o assoreamento do canal, já que os destroços são carreados com dificuldade pelo fluxo do rio.

\subsection{Caracterização de barras laterais}

Notou-se um padrão evolutivo semelhante entre as barras lateais, assim como nas ilhas. O mesmo ocorre devido à escassez de chuvas, que contribui com o processo "crescimento" dos depósitos, seja por sedimentação lateral da barra (BL 01 e BL 09) ou pela exposição de bancos arenosos (anteriormente submersos) em decorrência dos menores índices de vazão registrados (BL 02), como pode ser visto na figura 13.

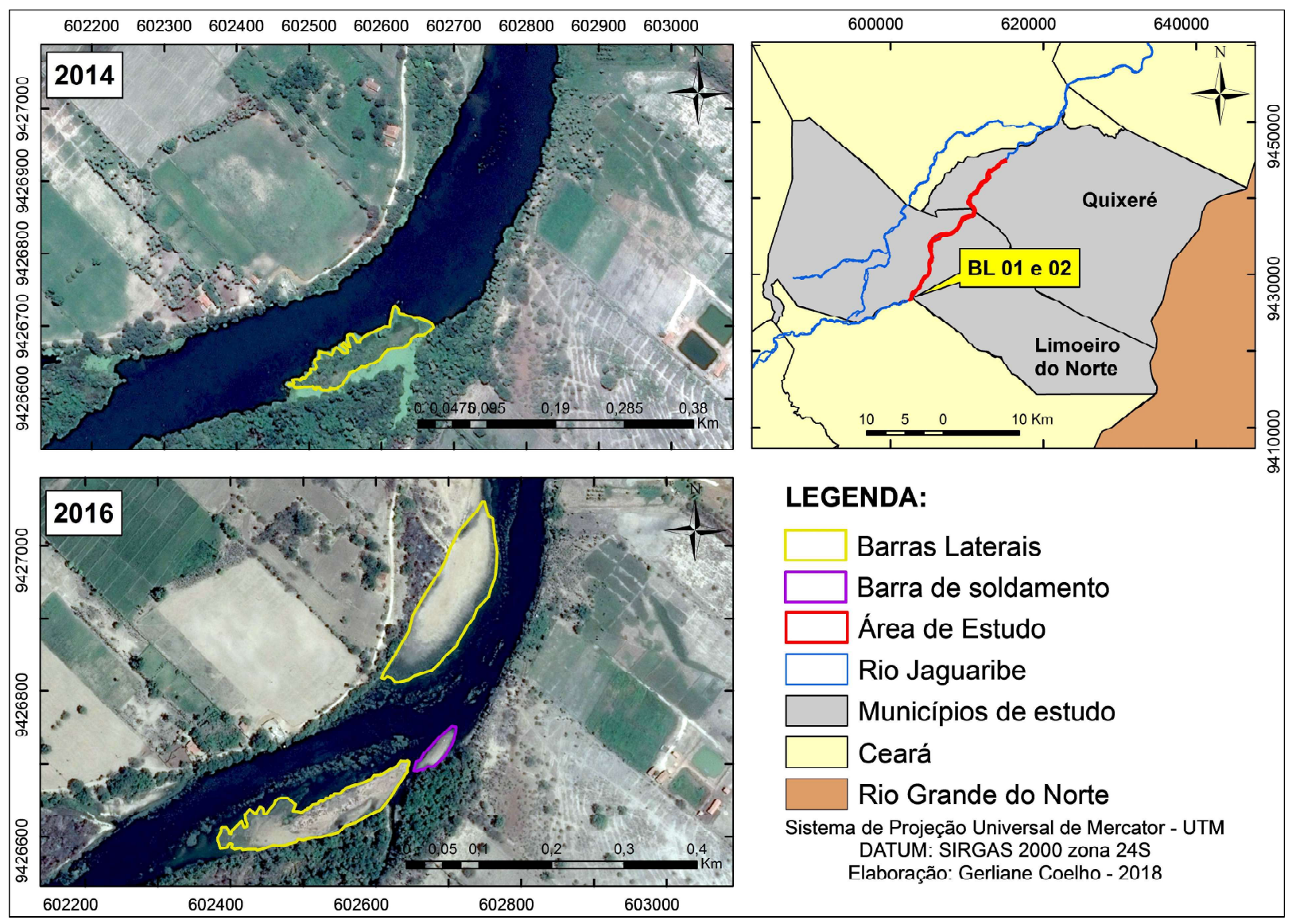

Figura 13 - Evolução e formação de barras laterais, localizadas 140 metros a montante da Barragem das Pedrinhas, no Município de Limoeiro do Norte-CE. Fonte: elaborado pela autora (2018).

A barra 01 foi visualizada pela primeira vez nas imagens de satélite de 2001, mas somente de 2014 para 2016 houve sedimentação lateral considerável, aumentando de $7.060 \mathrm{~m}^{2}$ para $11.773 \mathrm{~m}^{2}$ nesse período, um percentual de aproximadamente $66,8 \%$. A barra lateral 02 foi vista somente no ano de 2016, com área de 16.036 $\mathrm{m}^{2}$ (tamanho semelhante à barra 01).

Entre 2014 e 2016 foi verificada uma média pluviométrica de $466,1 \mathrm{~mm}$, ao passo que, as vazões médias registradas em $2014\left(17,5 \mathrm{~m}^{3} \mathrm{~s}\right), 2015\left(5,7 \mathrm{~m}^{3} \mathrm{~s}\right)$ e $2016\left(2,1 \mathrm{~m}^{3} \mathrm{~s}\right)$ foram regredindo substancialmente. A formação do depósito se deve pela exumação de bancos 
arenosos ou do próprio leito, anteriormente submersos, devido às baixas vazões.

A barra lateral 09 também é um depósito recente, assim como as feições citadas, no entanto, sua gênese poder ter origem diferente (Figura 14). Como a primeira aparição da barra nas imagens de satélite foi no ano
2010, acredita-se que o depósito foi formado em 2009, devido as grandes precipitações e vazões registradas naquele ano. Esses eventos climáticos proporcionam o remanejamento de sedimentos por todo o leito, devido processos excepcionais de erosão, transporte e deposição das partículas.

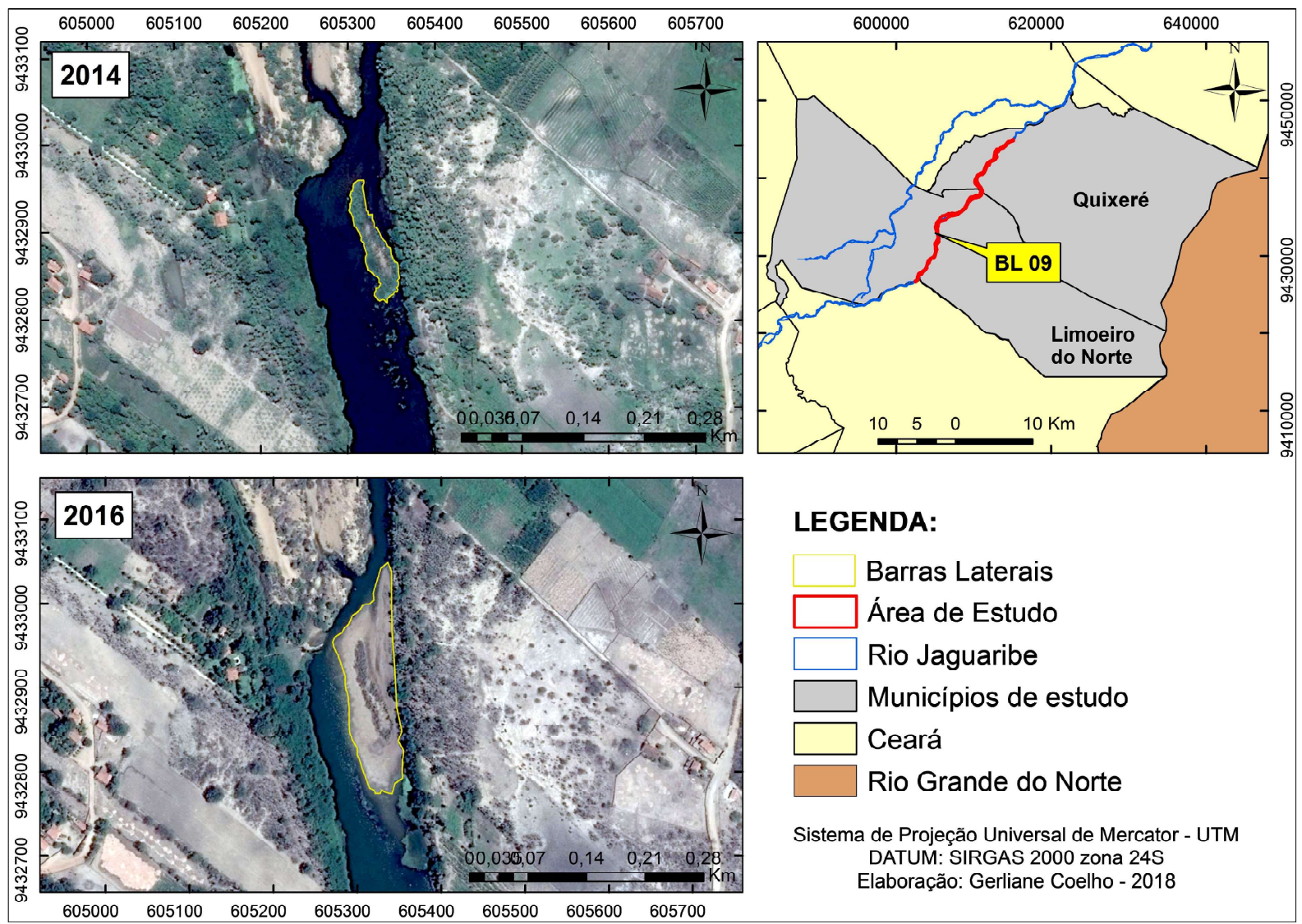

Figura 14 - Barra lateral recente, localizada no Município de Limoeiro do Norte-CE. Fonte: elaborado pela autora (2018).

A dinâmica de formação de barras fluviais no baixo curso do rio Jaguaribe acontece em consonância com a dinâmica das chuvas e vazões, de modo que, anos como 2009 proporcionam a redistribuição de sedimentos no canal e, consequente, incremento de depósitos sedimentares (QUEIROZ et al., 2018).

Foi possível observar no trabalho de campo, que a área ocupada pela barra em 2014, corresponde ao local onde se concentra a vegetação do depósito atualmente. A barra não teve mudanças significativas de 2011 para 2014, no entanto, de 2014 para 2016 houve um crescimento areal de $320,9 \%$, o maior registrado entre os 10 depósitos estudados detalhadamente, aumentando seu tamanho de $3.132 \mathrm{~m}^{2}$ para $13.183 \mathrm{~m}^{2}$.
A única coleta de sedimentos realizada na barra foi feita justamente na parte recente do depósito, local onde houve acreção lateral em 2016 (Figura 15). A composição granulométrica estava dividida em grânulos $(35,6 \%)$, areia grossa $(25,7 \%)$ e areia média $(25 \%)$, o que denota material grosseiro. Em resumo, a amostra colhida possuía características de leito, ou seja, o processo evolutivo do depósito é resultante da exposição de parte do fundo do canal, devido as baixas vazões registradas no período de seca.

A barra lateral 15, possui registros que datam de 1988, ano com precipitação de $891,2 \mathrm{~mm}$, pouco acima da média do baixo Jaguaribe $(704,5 \mathrm{~mm} / \mathrm{ano})$, ocupando uma área de $11.614 \mathrm{~m}^{2}$. Em 2009 o depósito passou a 
medir $18.019 \mathrm{~m}^{2}$, com crescimento areal de $24 \%$. Vale ressaltar que a morfologia da barra também foi alterada nesse período, deixando-a com uma característica mais alongada (Figura 16).

Os depósitos, mesmo após períodos de picos de flu- xo podem expor as feições a atuação de pequenas correntes modeladoras, levando-as a adquirir formas diferentes (QUEIROZ et al., 2018). Já em 2014 a feição recobria uma área de $19.614 \mathrm{~m}^{2}$, aumentando para e $24.448 \mathrm{~m}^{2} \mathrm{em}$ 2016, verificando-se crescimento areal de $20 \%$.

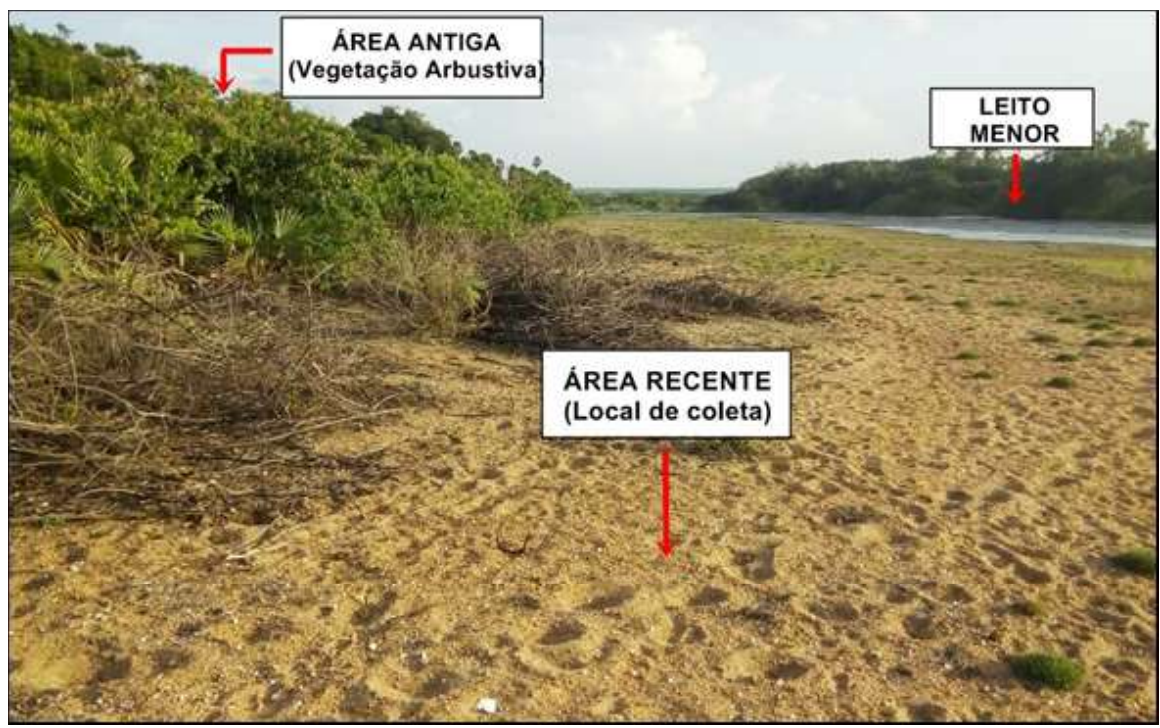

Figura 15 - Barra lateral recente, localizada no Município de Limoeiro do Norte. Fonte: acervo da autora (2018).

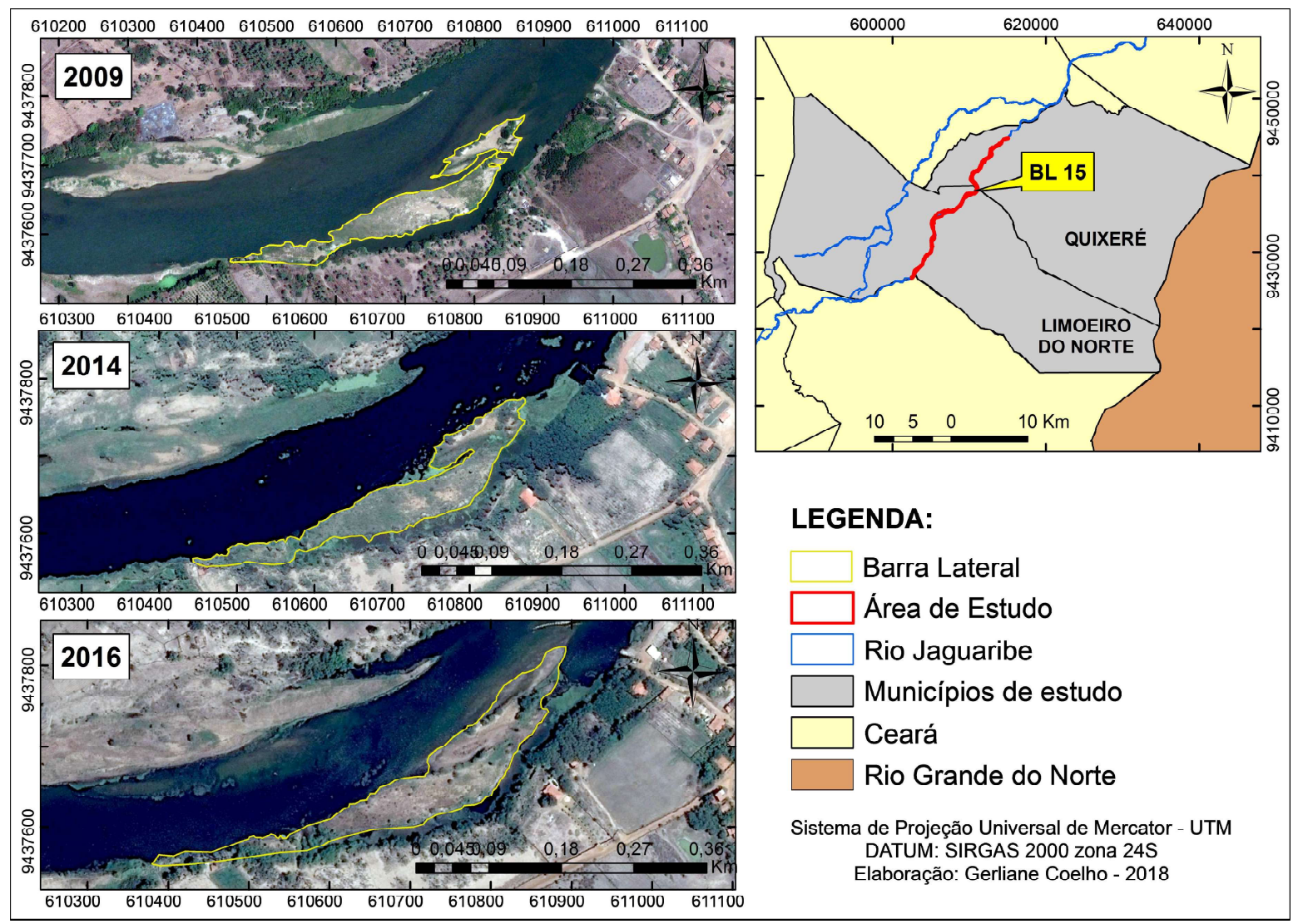

Figura 16 - Barra lateral localizada a montante da passagem molhada de Quixeré. Fonte: elaborado pela autora (2018). 
A composição granulométrica da barra varia de acordo com o local de coleta. Na parte alta, próxima a lateral esquerda do depósito, é encontrado material que se alterna entre areia fina (38\%) e areia média (27\%), o que pode indicar que essa área já funcionou como uma espécie de margem. A segunda coleta foi feita na parte recentemente adjunta a barra, com sedimentos grosseiros (26,5\% grânulos; $23,4 \%$ areia grossa; $22 \%$ areia média), possivelmente resultantes do próprio leito $(30,8 \%$ grânulos; $25,4 \%$ areia grossa; $20,7 \%$ areia muito grossa).
A barra lateral 15 não está fixada a margem direita do rio, mas acredita-se que em cenários futuros de escassez possa haver o soldamento total do depósito sedimentar. (Figura 17). O leito que fica entre a barra e a margem encontra-se totalmente vegetado por macrófitas e com fluxo lento, o que favorece a formação de zonas de sombra, propiciando a deposição de sedimentos. Posteriormente, o depósito passaria a ser classificado como uma barra de planície, dada sua área de ocupação (500m de comprimento) e capacidade de fixação.

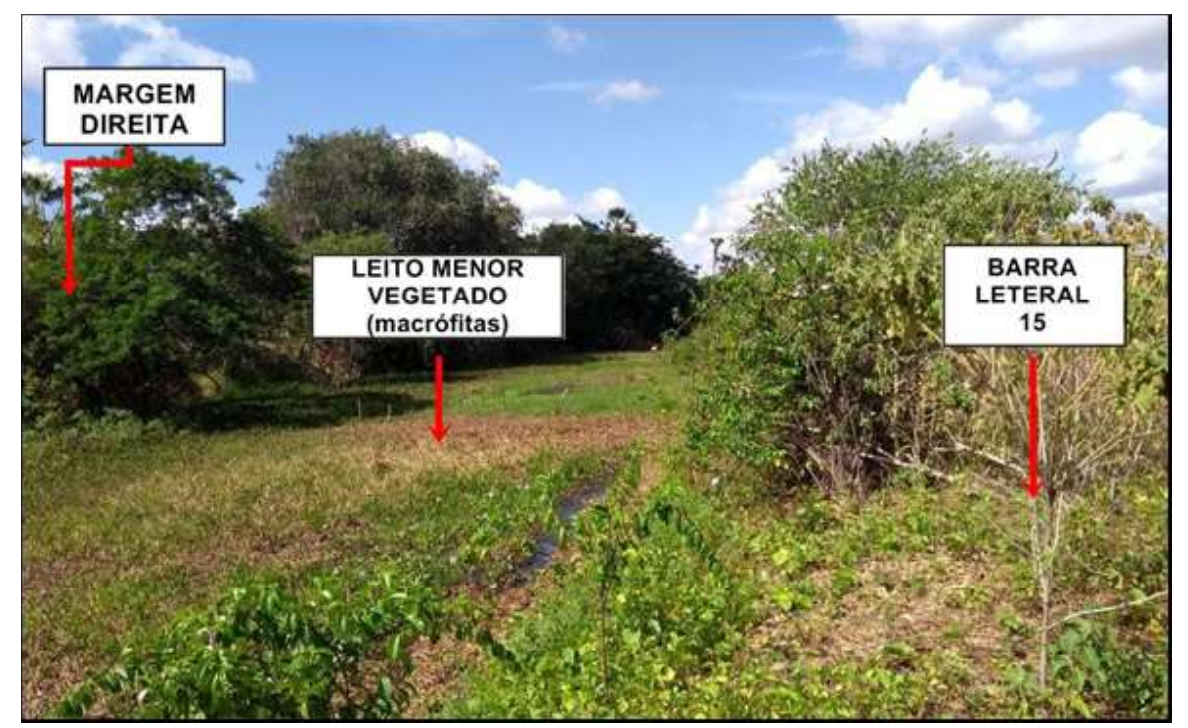

Figura 17 - Acúmulo de macrófitas aquáticas no leito menor, entre a "barra lateral 15" e a margem direita do rio. Fonte: acervo da autora (2018).

\subsection{Caracterização das barras de planície}

As barras de planície são consideradas, no presente estudo, como barras laterais anexadas a margens do rio, correspondendo na atual literatura, a própria planície de inundação. A diferenciação foi feita baseada principalmente na sua característica de fixação, distinguindo-se das barras laterais comuns que são mais facilmente erodidas e carreadas.

A barra de planície 13, representava uma porção areal de $122.698 \mathrm{~m}^{2} \mathrm{em} 2014$, ao passo que, em $2016 \mathrm{a}$ feição passou a ocupar $148.694 \mathrm{~m}^{2}$, aumento de $21 \%$. O crescimento areal é possivelmente o resultado da exposição de parte do leito devido à diminuição do fluxo, além do soldamento das barras de coalescência vistas em 2014 (Figura 18).

A barra de planície 17 é datada de 1958 (a mais antiga do estudo), embora na época não fosse classificada assim (Figura 19). O depósito, originalmente dividido em três barras laterais menores, recobria uma área conjunta de $141.418 \mathrm{~m}^{2}$. Em 1988, as barras mantiveram características morfológicas parecidas (aumentado também de tamanho), registrando um total de $182.708 \mathrm{~m}^{2}$.

A partir de observações de imagens de satélite do Google Earth Pro, observou-se que a barra de planície continuou obedecendo padrões semelhantes de 1988 a 2003, ao passo que, entre os anos de 2014 e 2016 houve mudanças significativas. Em 2014, a barra ainda estava dividida em três depósitos, duas barras laterais e uma central, somando uma área total de $116.684 \mathrm{~m}^{2}$, inferior ao registro de 1988 . No ano de 2016 as feições se soldaram formando somente uma feição, classificada como barra de planície. A mesma media 1,3 km de extensão, com aproximadamente $201.279 \mathrm{~m}^{2}$ de área e aumento percentual de $72,5 \%$ (Figura 20). 
Coelho G. K. S. \& Andrade J. H. R.

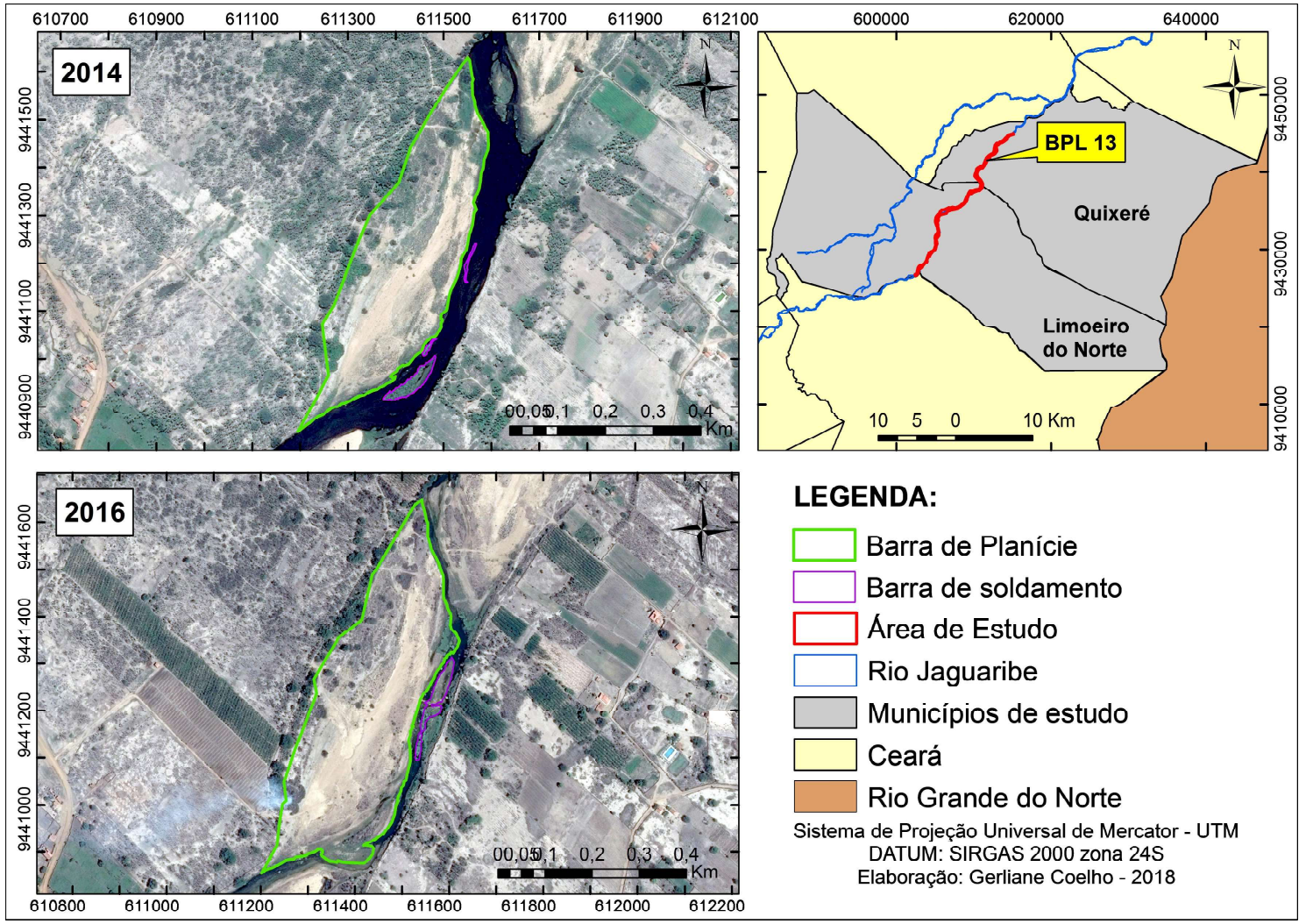

Figura 18 - Processo evolutivo da "barra de planície 13". Fonte: elaborado pela autora (2018).


LEGENDA:



Sistema de Projeção Universal de Mercator - UTM DATUM: SIRGAS 2000 zona $24 S$ Elaboração: Gerliane Coelho - 2018

Figura 19 - Dinâmica evolutiva de barra de planicie entre os anos de 1958 e 1988, anteriormente caracterizadas como barras laterais. Fonte: elaborado pela autora (2018). 


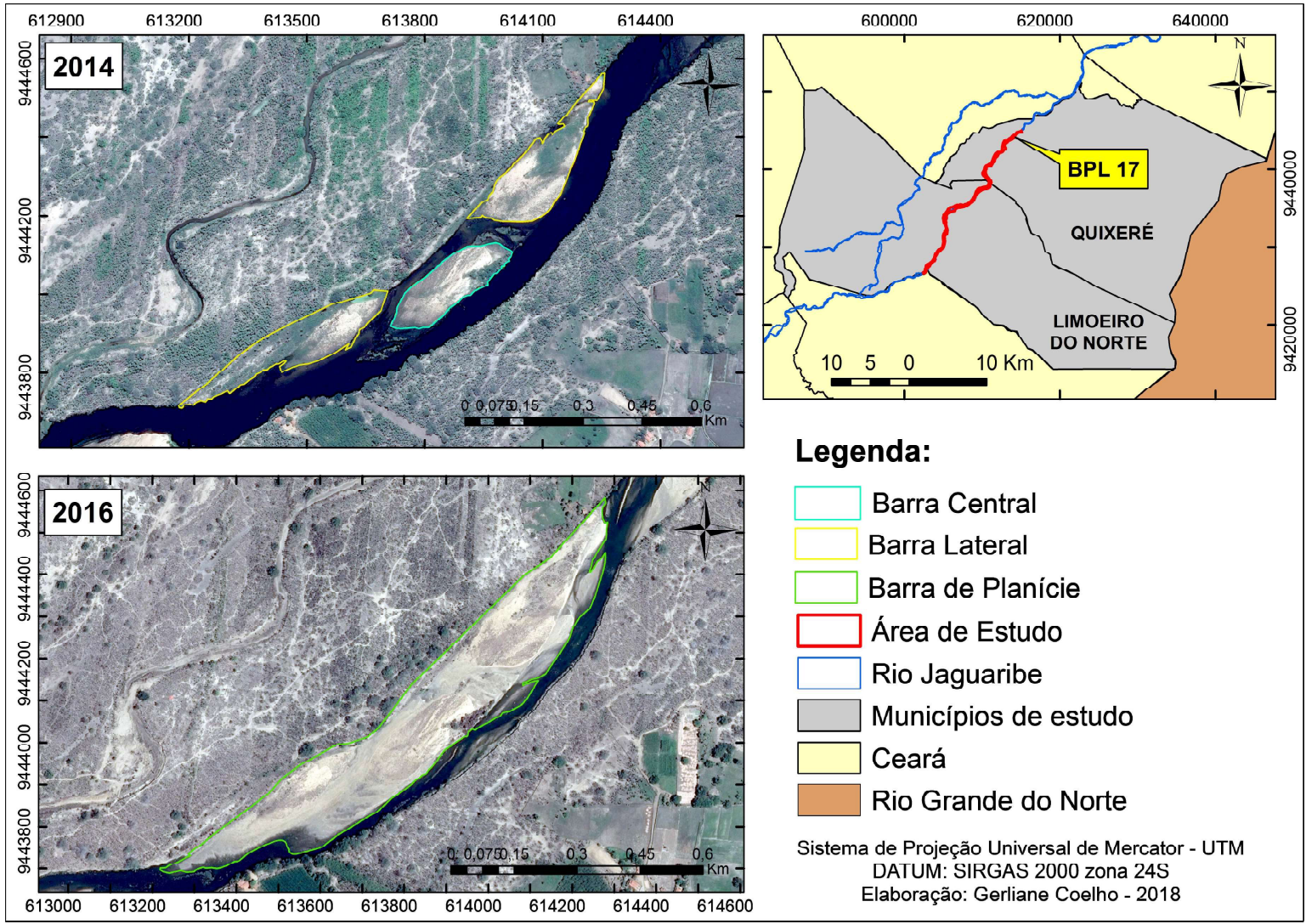

Figura 20 - Soldamento das barras laterais e posterior formação de uma barra de planície, no Munícipio de Quixeré. Fonte: elaborado pela autora (2018).

Considerando a cronologia das imagens disponíveis, foi possível averiguar que os depósitos não sofreram tanta sedimentação lateral como entre os anos de 2014 e 2016, isto é, o intervalo de tempo de 2 anos pode ter sido responsável por mudanças evolutivas mais críticas do que as observadas em 58 anos (1958-2014), se for considerado o impacto negativo que o assoreamento pode causar no canal.

Como as barras de planície possuem grande capacidade de fixação, a intensidade da ação dos processos erosivos é menor sobre elas, no entanto, os fenômenos deposicionais agem com mais propriedade, como observado em 2016, influência direta das baixas pluviometrias e vazões registradas no período de seca prolongada (2012-2016).

É possível observar, nas imagens de satélite de 2016, os caminhos percorridos pelo rio em períodos anteriores, mostrando que as barras de planície, devido sua magnitude (tamanho) funcionam como "aporte histórico" de mudanças no comportamento do padrão de canal do rio, mediante a alternância entre períodos secos e chuvosos.
Dentro de um estudo quantitativo e superficial das feições, o processo de sedimentação observado na barra de planície 17 passaria despercebido, uma vez que os dados mostrariam somente o acréscimo de um novo tipo depósito e a ausência de outros três. Portanto, torna-se importante uma análise detalhada dos depósitos, uma vez que o estudo permite considerar caminhos variados de evolução morfológica, complementando e aprofundado os dados quantitativos de área.

\section{Considerações finais}

As características climáticas do semiárido, como as chuvas torrenciais e secas prolongadas, eram até a década de 60 os únicos fenômenos que agiam substancialmente sobre a dinâmica dos depósitos, uma vez que os rios semiáridos possuíam características naturais de intermitência.

Em 1958, o leito não possuía fluxo continuo, portanto, eram os processos erosivos os responsáveis pelos principais impactos nas feições, tendo em vista, que os períodos chuvosos quando aliados à intermitência do rio, redistribuíam a carga sedimentar, mudando 
facilmente a morfologia e a localização dos depósitos. No ano de 1988 o cenário fluvial já apresentava um rio parcialmente perenizado, o que propiciou a regulagem de fluxo e maior estabilidade dos depósitos.

No que se refere à gênese das feições, foi possível verificar que geralmente acontece em resposta à redistribuição sedimentar ocorrida em períodos chuvosos, como visto em 2009. No entanto, ao analisar os anos de 2014 e 2016, foi possível observar que os baixos índices pluviométricos e de vazão (período de seca), além de estimular os processos deposicionais, também expõe bancos arenosos que antes faziam parte do próprio leito. Uma vez criados, os depósitos se desenvolvem substancialmente nesse período.

Como as feições encontradas em rios semiáridos possuem material granulométrico grosseiro (areia), sua força de coesão é menor, podendo ser facilmente carreado, como ocorria em 1958. No entanto, o controle de fluxo do rio Jaguaribe contribuiu para a diminuição dos processos erosivos e de redistribuição sedimentar no leito, diminuindo a mobilidade dos bancos arenosos. Uma vez estabilizados, acontece o processo de fixação, dado pelo crescimento vegetativo e sedimentação lateral. Agora, invés de transporta-lo, a energia do canal é responsável por moldar lentamente a morfologia do depósito,

A diferença de anos entre as fotografias pode prejudicar a análise evolutiva do depósito, devido os intervalos de tempo não registrados. No entanto, com base na cronologia dos eventos, verificou-se que as feições sofreram maior sedimentação entre 2014 e 2016.

É necessária a adoção de critérios de classificação terminológica pautados em características morfológicas para climas semiáridos, visto que, a má interpretação dos tipos de feição pode alterar todos os resultados da pesquisa. Além disso, propõe-se abordar a área de ocupação do depósito como critério de escolha relevante, partindo do pressuposto de que quanto maior a feição, maior também será sua resistência frente aos processos erosivos.

O estudo das barras e ilhas, numa perceptiva temporal, pode permitir a compreensão do comportamento sedimentar do rio e seu padrão de canal, uma vez que as feições funcionam como "marcas" históricas das mudanças de curso entre períodos secos e chuvosos, além de permitir a previsão de cenários futuros, para prevenção de impactos negativos como o assoreamento do canal.
A expansão areal das feições morfológicas pode acelerar o processo de assoreamento do rio, uma vez que os sedimentos são barrados pelo próprio depósito, influenciando no processo de decantação das partículas.

A utilização de imagens de satélite do Google Earth Pro foi feita a partir de uma proposta metodológica de alternativa gratuita e boa qualidade para coletada de dados recentes. Sua utilização foi satisfatória para a análise a curto prazo, além de servi como ferramenta de planejamento de campo.

\section{Referências Bibliográficas}

AB' SABER, Aziz Nacib. Participação das superfícies aplainadas nas Paisagens do Nordeste Brasileiro. Geomorfologia. São Paulo: IGEOG / USP, n.19, 1969.

AB' SABER, Aziz Nacib. O suporte geoecológico das Florestas Beiradeiras (Ciliares). In: RODRIGUES; R. R.; LEITÃO FILHO, H. F. (Org). Matas Ciliares: Conservação e Recuperação. São Paulo: EDUSP/FAPESP, 2000.

AB' SABER, Aziz Nacib. O Os domínios de natureza no Brasil: potencialidades paisagísticas. São Paulo: Ateliê Editorial, 2003.

ANDRADE, Manuel Correia de. A terra e o homem no Nordeste. 6. ed. São Paulo:Brasiliense, 1964.

ANDRADE, José Hamilton Ribeiro. Dinâmica de margens em rios semiáridos: aplicações metodológicas no rio Jaguaribe - Ceará - Brasil. Dissertação (Mestrado em Geografia), Universidade Federal rural do semiárido, 2016.

BEZERRA, Marcos de Brito. Impactos de passagens molhadas na morfodinâmica fluvial do baixo curso do rio Jaguaribe: uma análise a partir da barragem das pedrinhas em Limoeiro do Norte - Ceará. Dissertação (Mestrado em Geografia), Universidade Estadual do Ceará, 2010.

CAVAlCANTE, Andrea Almeida. Aspectos da Produção de Sedimentos e seus Efeitos na Gestão dos Recursos Hídricos do Baixo Vale do rio Jaguaribe-Ce. Dissertação (Mestrado em Geografia) - Universidade Estadual do Ceará, Fortaleza, 2001.

CAVAlCANTE, A. A. Morfodinâmica fluvial em rios semiáridos: $O$ rio Jaguaribe a jusante da barragem do Castanhão - CE - Brasil. Tese (Doutorado em Geografia). Universidade Federal Fluminense, Niterói, 2012.

CAVALCANTE, Andrea Almeida; CUNHA, Sandra Baptista. Morfodinâmica fluvial em áreas semiáridas: discutindo o vale do rio Jaguaribe-Ce-Brasil. Revista Brasileira de Geomorfologia, 
v. 13, n. 1, p.39-49, 2012.

CHRISTOFOLETTI, A. Geomorfologia fluvial. São Paulo: Edgard Blucher, 1981.

CHISTOFOLETTI, A. Modelagem de sistemas ambientais. São Paulo: Edgard Blücher, 1999.

CHRISTOFOLETTI, A. Análise de Sistemas em Geografia. São Paulo: Hucitec, 1979.

CHRISTOFOLETTI, A. Geomorfologia fluvial. In: Geomorfologia. 2.ed. São Paulo: Editora Blucher, 1980.p. 65-101.

COSTA, Cleuton Almeida. Marcas da ocupação do solo na dinâmica fluvial do médio-baixo Jaguaribe-ce. Dissertação (Mestrado em Geografia), Universidade Estadual do Ceará, 2009.

COGERH. Anuário do Monitoramento Quantitativo dos Principais Açudes do Estado do Ceará. Fortaleza: Companhia de Gestão dos Recursos Hídricos (COGERH), 2007.

CUNHA, S.B. da. Bacias Hidrográficas. In: CUNHA, S. B.; GUERRA, A. J. T. (org.). Geomorfologia do Brasil. Rio de Janeiro: Bertrand Brasil, 1998. p. 229-272.

CUNHA, S.B. da. Geomorfologia Fluvial. In: GUERRA, A.J.T.; CUNHA, S.B. (org.) Geomorfologia uma Atualização de Bases e Conceitos. $4^{\text {a }}$ ed. Rio de Janeiro: Bertrand Brasil, 1995.

CUNHA, Sandra Batista da (Org.). A questão ambiental: diferentes abordagens. 5. ed. Rio de Janeiro: Bertrand Brasil, 2010. Cap. 7, p. 219-237.

CUNHA, S. B .da. Geomoforlogia e meio ambiente. $10^{\circ}$ ed. Rio de Janeiro: Bertrand Brasil, 2011. p. 337-380.

FERNANDEZ, O. V. Q; SANTOS, M. L; STEVAUX, J. C. Evolução e características faciológicas de um conjunto de ilhas no rio paraná, região de Porto Rico (PR). Boletim de Geografia, v. 01, n. 1, 1993.

FILHO, E. E. S; RIGEN, B. T. C. Avaliação da velocidade de deslocamento de barras fluviais do Rio Paraná por meio de imagens CBERS/CCD. Revista brasileira de geomorfologia, v. 13, n. 1, 2012.
GUERRA, Antônio José Teixeira; CUNHA, Sandra Baptista da. Geomorfologia: uma atualização de bases e conceitos. Rio de Janeiro: Editora Bertrand Brasil, 1994.

KNIGHTON, A. D.; NANSON, G. C. Waterholes and their significance in the anastomosing channel system of Cooper Creek, Autralia. Geomorphology, 9 (4), p.311-324, 1994.

LIMA, I. M. M. F; AUGUSTIN, C. H. R. R. Bacia hidrográfica do Rio Poti: Dinâmica e morfologia do canal principal no trecho do baixo curso. Revista Geonorte, v. 10, n. 1, 2014.

NANSON, G.C.; CROKE, C. A genetic classification of floodplains. Geomorphology. 4, 459-486, 1992.

PREES, Frank; SIEVER, Raymond; GROETZINGER, John; JORDAN Thomas H. Para Entender a Terra. Trad. Rualdo Menegat et al.. 4 ed. Porto Alegre: Bookman, 2006.

RICCOMINI, Claudio et al. Rios e processos aluviais. In: TEIXEIRA, Wilson et al (Org). Decifrando a terra. 2 ed. São Paulo: Oficina de Textos, 2003. pág. 191-202.

SANTOS, M. L. S; FERNANDEZ, O. V. Q; STEVAUX, J. C. Aspectos morfogenéticos das barras de canal do rio Parará, trecho de Porto Rico, PR. Boletim de Geografia, v. 10, n. 1, 1992.

SOUZA, J. O. P. Dos sistemas ambientais ao sistema fluvial uma revisão de conceitos. Caminhos de Geografia, v. 14, n. 46, 2013.

SUGUIO, K. Introdução a Sedimentologia. São Paulo: Edgard Blücher, Ed. da Universidade de São Paulo, 1973.

SUGUIO, K.; BIGARELLA, J.J. Ambientes Fluviais. $2^{\mathrm{a}}$ ed. Florianópolis: Editora da UFSC: Editora da Universidade Federal do Paraná, 1990. 183p.

TEIXEIRA, W. et. al. (org.). Decifrando a Terra. São Paulo: Oficina de Textos, 2000. 2a reimp. 2003. p. 192-214.

TOOTH, S.; NANSON, G. C. Anabranching rivers on the Nothern Plains of and Central Autralia. Geomorphology, 1999. QUEIROZ, et al. Caracterização multitemporal de barra e ilhas fluviais no Baixo Curso do Rio Jaguaribe, Ceará-Brasil. Revista brasileira de Geomorfologia, v. 19, n. 1, 2018. 